\title{
1 Seal failure assessment of a major gas field via 2 integration of seal properties and leakage 3 phenomena
}

$4 \quad$ M. Foschi $^{1 *}$ and J.A. Cartwright ${ }^{1}$

$5{ }^{1}$ Shell Geoscience Laboratory - Department of Earth Science, University of Oxford, South Parks Road,

6 Oxford OX1 3AN, UK

7 *martinof@earth.ox.ac.uk

\section{Acknowledgments}

11

We thank the National Offshore Petroleum Titles Administrator (NOPTA) for the free access to seismic data, well data and reports. We are grateful with Schlumberger for providing software support. We thank Andy Aplin and Bruce Levell for discussion on seal capacity and leakage. We also thank Matteo Paganoni and James King for their constructive discussions and comments on an earlier version of the manuscript. We thank Elena Konstantinovskaya, Robert Locklair, Kurt Rudolph, and Hanneke Verweij for their invaluable reviews and for helping to improve this manuscript significantly.
Abstract
We present a seismic and well-based interpretation of a large 'leakage zone' above the Scarborough Gas Field, Exmouth Plateau, NW shelf of Australia. This leakage zone, well imaged on 3-D seismic, extends over a region of $100 \mathrm{~km}^{2}\left(38.6 \mathrm{mi}^{2}\right)$ encompassing both the crest and flanks of the anticlinal trap, and is termed here as Distributed Crestal Leakage. The present-day gas-water contact is $85 \mathrm{~m}(278 \mathrm{ft})$, and the spill point is $110 \mathrm{~m}(328 \mathrm{ft})$ below the crest, implying that the trap is underfilled at present. The leakage zone comprises over 500 pockmarks at the present-day seabed with no crosscutting or cannibalization, suggesting that they formed in a short interval of time. These are underlain by sediment remobilization features and amplitude anomalies, consistent with a relatively high flux leakage of gas from the underlying Cretaceous deep-water sand-rich reservoir. By analyzing the geometrical relationship between the leakage zone, the top seal properties, and the gas-water contact, we conclude that the mode of leakage in this specific setting is not the result of gradual addition of gas charge but is instead consistent with a sudden increase of aquifer overpressure. We suggest two alternative models for seal failure in this case study: a conservative model consistent with a modest but rapid increase in aquifer overpressure leading to membrane seal failure, and a model dominated by high aquifer overpressure leading to leakage through hydraulically dilated faults and fractures. 
Leakage from top seals is a major cause of failure in exploration, resulting in underfilled or completely blown traps and in many sub-commercial discoveries (Downey, 1984; Rudolph and Goulding, 2017). Top seal failure leading to significant leakage is also a major risk for carbon sequestration in shallow saline aquifers (Chadwick et al., 2008), and is a particular point of focus for regulators (Bruant et al., 2002). A comprehensive understanding of the causes of top seal failure underpins all efforts to mitigate these risks, but with limited predictive capability to date and an estimated $50 \%$ of dry holes being attributable to some

42 form of trap and seal failure (Rudolph and Goulding, 2017).

43 The theoretical foundations for top seal risking were established in a series of seminal papers published in 44 the 1970s and 80s (Berg, 1975; Schowalter, 1979; Du Rouchet, 1981; Downey, 1984; England et al., 45 1987; Watts, 1987; Sales, 1997). These pioneering contributions emphasized the role of buoyancy pressure in determining seal capacity, whereby the maximum buoyancy pressure of a trapped

47 hydrocarbon column (gas or oil or both) would be exerted on the base of the top seal at the position of the maximum hydrocarbon column (MHC; Figure 1A). For membrane seal failure (Schowalter, 1979), the failure would occur where the buoyancy force exceeded the capillary entry pressure of the top seal. For a homogeneous top seal with laterally uniform capillary properties, membrane leakage would occur at the

51 position of MHC, which would typically be at the crestal point or close to that position (Figure 1A; Sales, 52 1997). Similarly, the likeliest point of failure of a seal through a mechanical or hydraulic seal failure mechanism (Watts, 1987) would also be at the MHC position, where the buoyancy pressure exceeds the 54 minimum horizontal stress plus the tensile strength (Ingram and Urai, 1999). Hydrodynamic conditions 55 in the aquifer would affect the column height required to achieve the match with either membrane or 56 hydraulic seal failure conditions, and overpressured aquifers would be predicted to support smaller 57 hydrocarbon columns than hydrostatically pressured aquifers (Schowalter, 1979; Heum, 1996).

58 Many traps are underfilled relative to the ultimate trap capacity defined by their spill points and this 59 points to a limiting factor related either to hydrocarbon charge, or to leakage from top or lateral seals 60 (Rudolph and Goulding, 2017). For a trap undergoing continuous charge, the trap would continue to fill 
61 up to the spill point or until top seal failure and leakage occurred (Schowalter, 1979; Watts, 1987; Sales,

62 1997). Where top seal failure occurs before fill to spill, then it can be inferred that a critical column height

63 was reached (Class 2 and 3 traps, c.f. Sales, 1997), whereby any additional charge would increase the

64 column height such that the maximum buoyancy pressure exceeded either the membrane or the hydraulic

65 seal capacity (Figure 1B). Once the column height exceeds the seal capacity, any additional charge is

66 valved off through the leakiest portion of the top seal, resulting in a periodic, small scale discharge from

67 the weakest point in the seal, typically located directly above or close to the MHC position (Figure 1B)

68 (Showalter, 1979; Heum, 1996; Sales, 1997). So for leakage that is essentially the result of addition of

69 hydrocarbon charge into an underfilled trap, a highly focused leakage geometry would be the predicted

70 result, with the likeliest focus for the leakage being close to the position of the MHC. Deviations from

71 this expected geometry have been noted in cases where there are thief zones (high permeability layers

72 within the seal) or permeable faults that intersect the top reservoir downflank from the $\mathrm{MCH}$ position

73 (Hermanrud et al., 2014).

74 For traps receiving continuous, or semi-continuous charge, once the seal capacity is reached, a prolonged,

75 but low flux leakage would be expected as long as there is charge to increase the column height beyond

76 the seal failure threshold value (Sales, 1997) (Figure 1B). This type of leakage above hydrocarbon

77 accumulations worldwide in the form of gas chimneys or gas clouds is widely observed (Heggland, 1997;

78 Arntsen et al., 2007). The precise leakage geometry is often not possible to establish in these cases,

79 because of the poor imaging quality of reservoirs beneath gas chimneys on seismic data (Heggland,

80 1997). For ease of reference below, we refer to this mode of leakage as Localized Crestal Leakage, where

81 there is a single locus of leakage located close to or at the crest of the structure.

82 We present a case study of top seal leakage above a major gas field (the Scarborough Gas Field, NW

83 Shelf of Australia) where the seal bypass was evidently so efficient that just a minimum amount of

84 hydrocarbons were trapped in the seal and overburden, and no gas chimney developed as a result. This

85 means that the top seal and overburden are very well imaged above the field on a 3D seismic survey,

86 allowing us to map the seal bypass systems and seismic indicators for fluid flow and hence define the 
87 leakage geometry (Cartwright et al. 2007). The seismic data shows that the leakage geometry contrasts markedly from that described above for localized crestal leakage, in that there are a number of leakage

89 loci, rather than a single crestal focus, and that these occur over a large region (c. $\left.100 \mathrm{~km}^{2}\left[38.6 \mathrm{mi}^{2}\right]\right)$ of 90 the anticlinal trap, extending well down flank from the ultimate crestal position.

91 The near surface fluid expulsion features linked to the gas leakage strongly suggest that seal failure

92 occurred in a geologically instantaneously manner in a single event. We discuss the failure conditions

93 resulting in the leakage event, and that this type of distributed leakage geometry and geologically

94 instantaneous timing of leakage cannot result from addition of gas charge. We then propose two models

95 for seal failure in this setting: Model A, consistent with modest aquifer overpressure leading to membrane

96 seal failure across top seal and overburden, and Model B, dominated by high aquifer overpressure leading

97 to leakage through hydraulically opened faults and fractures. Both models are assessed and evaluated in

98 relation to seal properties and the leakage mechanism that are require to justify the emplacement of the

99 leakage phenomena observed above the Scarborough Gas Field.

\section{SEISMIC AND WELL DATA}

This study is based on a combination of high-resolution multichannel 2D seismic profiles, a 3D seismic volume, and well-log data from the NW Shelf of Australia (Figure 2). The 2D seismic grid AR NWS

104 Regional and the HEX03A Scarborough 3D MSS three-dimensional seismic volume were released by the

105 National Offshore Petroleum Titles Administrator (NOPTA) and made available for academic research 106 purposes along with well data and selected well reports. The seismic cube, which is the key seismic data

107 of this study, was acquired and processed by Western Geco in 2004. The acquisition was carried out using

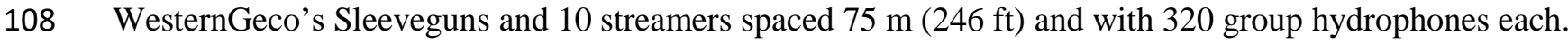

109 The data was processed using a standard sequence for marine data and finalized to zero-phase European 110 polarity convention (increase of acoustic impedance with depth is represented by a negative amplitude 111 response; negative reflection coefficient = peak). The data is characterized by a vertical resolution of 7-10 
$112 \mathrm{~m}(22-32 \mathrm{ft})$ in the reservoir interval and shallower (Widess, 1973). The in-line and $\mathrm{x}$-line spacing are $11312.5 \mathrm{~m}(41 \mathrm{ft})$ and $18.75 \mathrm{~m}(61 \mathrm{ft})$, respectively.

114 The seismic volume HEX03A Scarborough 3D MSS was depth converted using 924 velocity functions

115 provided by NOPTA. The velocity functions were firstly smoothed with an operator of $300 \mathrm{~ms}$ in length, 116 and secondly combined to get an interval velocity field for the calculation of the time to depth conversion. 117 A QC of the individual functions was not possible because common mid points and relative semblance 118 displays were not available.

119 The creation of the velocity field and the time to depth conversion were completed using Hampson120 Russel software. The interpretation of the leakage phenomena, analyzed on the time volume, and the 121 horizons, produced by gridding of horizons picked on the depth-converted volume, were completed using 122 Schlumberger's Petrel software.

THE SCARBOROUGH GAS FIELD

\section{Geological Context}

The Scarborough Gas Field is located in the Exmouth Plateau, Carnarvon Basin (Figures 2A). The basinal

127 context is that of a rifted passive margin (the NW Shelf region) that now constitutes one of the major 128 hydrocarbon producing regions in Australia, with >130 trillion cubic feet of known reserves (Longley et 129 al., 2001; Drenth, 2007).

130 The basin experienced a number of rift phases in the Triassic, Late Jurassic, and Early Cretaceous, 131 expressed as an extensive array of large normal faults (Figure 2B-D). Clastic reservoirs were sourced 132 from the hinterland and transported to the basin to the northwest. The most widely exploited play in the 133 basin is based on reservoirs of Triassic age, such as the non-marine Mungaroo-Locker Formation (Boyd 134 et al. 1992). The Scarborough Field is reservoired in turbiditic sandstones of the Barrow Group (Early 135 Cretaceous) (Unit 1; Figure 2B). The immediately overlying Muderong Shale (Unit 2; Figure 2B-C) is a 136 deep marine hemipelagite deposited during the Mid Cretaceous and is the immediate top seal in the 
Scarborough Field. Unit 2 is transected by a laterally extensive polygonal fault system (Cartwright, 2011), consisting of closely spaced normal faults with throws of a few tens of meters (Alrafee et al. 2018). Unit 3 was succeeded during the Late Cretaceous and Early Cenozoic by mainly pelagic carbonate mudstones (Unit 3; Figure 2B-C). A polygonal fault system, but a younger tier than that affecting Unit 2 also transects Unit 3, with little evidence of cross-tier propagation (Alrefaee et al. 2018; Figure 2C-D). The

142 faults in Unit 2 and 3 exhibit a classical polygonal pattern with no evidence of any anisotropic horizontal 143 stresses during their propagation (Figure 3A-B). The many faults in Unit 3 all tip out upwards at or very 144 close to a prominent regional unconformity (Middle Miocene Unconformity; H1, Figures 2B-D, 3C) that 145 formed during a major compressional event during the mid-late Miocene (Hillis et al., 2008). The unconformity was sculpted by erosion in a deep-water setting under the influence of strong bottom currents (Nugraha et al., 2018). Tectonic compression led to the formation of NE-SW oriented structures across the basin, including the anticline hosting the Scarborough Gas Field (Jablonski et al., 2013). This compressional phase resulted in minor reactivation of tectonic normal faults and other inversion structures, such as minor parasitic folds (Figure 2C-D). There is no evidence of any reactivation of the polygonal faults in either Unit 2 or 3

152 during this phase of deformation (Figure 3C, 4A-B). The compression waned and died in the Late 153 Miocene. Mid to late Miocene sediments (lowermost Unit 4; Figure 2B-3) onlap the flank of the 154 Scarborough anticline suggesting that growth of this fold gradually died out during this interval (Figure 4A-C). This was followed by the pelagic drape of dominantly fine-grained carbonate successions (Unit 4;

156 Figure 2B, 4A-C). No evidence of tectonic activity is evident at the present day in the NW Shelf region or 157 above the Scarborough Field, although the maximum horizontal stress based on borehole breakouts and 158 drilling-induced tensile fractures, is oriented perpendicular to the Miocene-aged fold axes $\left(\sim 113^{\circ} \mathrm{N}\right.$, 159 Bailey et al., 2016). 
The Scarborough Field was discovered in 1979, and subsequently five more wells and the 3D volume HEX03A Scarborough 3D were completed as a part of prolonged exploratory and appraisal campaigns under different operators. These well and data provided the information to characterize the properties and the geometries of the trap, the seal and the reservoir.

166 The trap of the Scarborough Gas Field is a four-way dip closure on an NNE elongated anticlinal dome

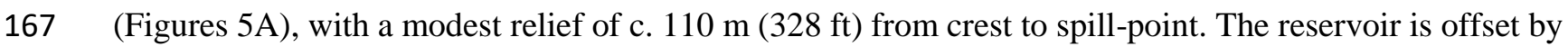
168 a number of NNE-SSSW and ENE-WSW trending normal faults (O'Halloran, 2006) with relatively 169 modest throws of 10 to $20 \mathrm{~m}$ (32 to $65 \mathrm{ft}$ ) at top Reservoir (Figure 5B). These faults have much larger 170 throws at the Triassic level, and their activity was quite limited within the Cretaceous (Bilal et al., 2018).

171 They die out upwards in the middle of Unit 3 with no clear evidence of reactivation in this unit and in 172 Unit 4 (Figure 2D).

173 The reservoir interval is composed of two main sand-rich basin-floor fans, namely the Lower Fan and the 174 Upper Fan, with an average porosity of $20-30 \%$ and a permeability of over $2000 \mathrm{mD}$. A prominent 175 seismic flatspot (1) is mappable over the area of the field, (2) conforms to structure, and (3) matches the 176 gas water contact (GWC) defined in the exploration and appraisal wells at $1916 \mathrm{~m}$ TVDSS (6286 ft;

177 Figure 2B, 4A). The two reservoir units are in pressure communication as observed by the continuous and 178 linear gas pressure gradients across these two sand rich formations (Figure 6A). Reserves of 7.3 trillion 179 cubic feet of dry gas (95\% methane, $4 \%$ nitrogen) have been declared. The MHC is $84.7 \mathrm{~m}$ (278 ft; at 180 well Scarborough-4; Locke, 2005). The water leg within the reservoir interval is hydrostatically pressured 181 at the present day (Figure 6A). The trap is underfilled, with c. $35 \mathrm{~m}$ (c. $114 \mathrm{ft}$ ) of vertical separation 182 between the actual gas-water contact and the spill-point.

183 The immediate top seal for the Scarborough Field is represented by the Muderong Formation (Unit 2, 184 Figure 2B). In the field area, this is composed of c. $200 \mathrm{~m}(656 \mathrm{ft})$ of relatively homogeneous claystones 185 with minor intercalations of limestone and silt (Figure 6B). The permeability of the Muderong Formation 186 has been measured as $300 \mathrm{nD}$ (Chen et al., 2014). The log signature is similarly uniform, with high 187 gamma values throughout the interval (Figure 6B). Unit 2 is pervasively deformed by a polygonal fault 
system (Alrafaee et al. 2018). There is no preferred orientation to these faults, as already observed in

Figure $3 \mathrm{~A}$, and their spacing is a few hundred meters. Their maximum throws are typically less than $20 \mathrm{~m}$

(65 ft), and they die out at the Top Reservoir without offsetting this boundary (Figure 4A).

Leak-off test (LOT) results derived from the wells Scarborough-1 to 5 are plotted on a Pressure-Depth

192 plot for the Scarborough Field along with mud weight data and fluid pressures within the water and gas

193 legs (Figure 6A). The fracture gradient within the Muderong Formation is represented as a corridor to

194 reflect the uncertainty in the LOT results and their distribution. The fracture gradient plotted in Figure 7 is

195 a good match with the plot of minimum horizontal stress obtained from LOTs and Formation Integrity

196 Tests from a larger well compilation of the Muderong Formation in the nearby Carnarvon Basin

197 (Dewhurst and Hennig, 2003; Figure 7, inset). Simple construction assuming a constant gas gradient, as

198 derived from the wells in the field, shows that the Muderong Formation seal has a hydraulic seal capacity

199 (Watts et al., 1987) of between 530 and $760 \mathrm{~m}$ (1738 and $2493 \mathrm{ft}$ ) for gas (Figure 7). Because of the large

200 number of faults and fractures a lower seal capacity is expected. Using the maximum mud weight profile

201 (Scarborough-1) as representative of the most conservative value for seal capacity, a maximum gas

202 column of $368 \mathrm{~m}(1207 \mathrm{ft})$ is obtained (Figure 7).

203 The membrane seal capacity is uncalibrated for the Muderong Formation in the Scarborough Gas Field,

204 so we rely instead on a suite of measurements taken from exploration wells drilled about $200 \mathrm{~km}$ (124 mi)

205 SE of the study area. Dewhurst et al. (2002) analyzed a $4 \mathrm{~m}(13 \mathrm{ft})$ long cored section taken directly above

206 the reservoir in the lowermost Muderong Formation at $1120 \mathrm{~m}(3674 \mathrm{ft})$ below the seafloor. They

207 computed values using a variety of methods and they obtained a mean value of $262 \mathrm{~m}(\mathrm{SD}=15.05)(860$

$208 \mathrm{ft}$ ) of equivalent gas column height for the local reservoir pressure and temperature conditions. In a later

209 study, Kovack et al. (2004) extended these measurements to include mercury injection capillary pressure

210 and compositional data from 24 wells over a large region of the Carnarvon Basin, located some $200 \mathrm{~km}$

211 (124 mi) SE of our study area. They found that the Muderong Formation exhibits a wide range of

212 threshold pressure from 40 to 10,000 psi. Using the same database compiled by Kovack et al. (2004), but

213 restricting the measurements to seven wells where the Muderong Formation is encountered at the same 
214 depth range as in our study area, a mean value of threshold pressure of $1725 \mathrm{psi}(\mathrm{SD}=716)$ was observed

215 (11 MPa). The average gas column height of this subset of data in Kovack et al. (2004) calculated using

216 in situ conditions, is $171 \mathrm{~m}(\mathrm{SD}=75)(561 \mathrm{ft})$ and equivalent to $1.5 \mathrm{MPa}$ (Figure 7). Both the locally

217 derived hydraulic seal capacity (Figure 7) and the membrane seal capacity taken from Dewhurst et al.

218 (2002) and Kovack et al. (2004) exceed the trap capacity.

219 A pronounced leakage zone has previously been recognized in the overburden and at the seabed in the

220 south-central part of the field (Cowley and O'Brien, 2000; Jablonski et al. 2013) but no detailed analysis

221 of geometry, timing or mechanism of leakage has been undertaken in previous studies.

222

223 LEAKAGE ZONE

224 The leakage zone was defined in our study by interpreting features indicative of gas migration through the

225 units overlying the top reservoir, and up to the present-day seabed. These are described below in a top-

226 down order on the HEX03A Scarborough 3D MSS time volume.

\section{Seabed}

229 The seabed exhibits smooth morphology and no signs of active erosion or disruption over most of the

230 survey area (Figure 2D). The near surface sediments are not age calibrated in this area (no public domain

231 data are available), but correlation using 2D seismic profiles to ODP 763, suggests that the first tens of

232 meters could be Middle to Late Quaternary in age. This smooth seabed morphology is characteristic of

233 the slow pelagic deposition in the area, but remarkably it is punctuated by a large sub-circular region of

234 highly irregular seabed topography centered above the south-central part of the field (Figure 8A). A total

235 of 522 small seabed depressions are mapped in the 3D seismic survey within an area of c. $100 \mathrm{~km}^{2}(38.6$

$236 \mathrm{mi}^{2}$ ). The depressions are demonstrably erosional (original sediments have been blown out by gas

237 expulsion; Figure 8A-B), exhibit closed perimeters, with circular to sub-circular planforms and occur in a

238 series of regions with high spatial density (Figure 8A). They typically measure 250-350 m (820-1050 ft) 


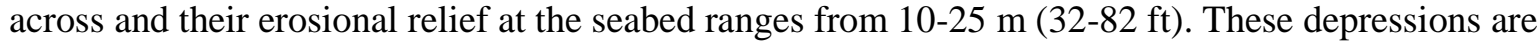

240 interpreted as seabed pockmarks, based on their erosional character, planform, distribution and context

241 (c.f. Judd and Hovland, 2009).

243 Unit 4

244 Unit 4 is bounded at its top by the seabed and at its base by the Middle Miocene Unconformity, shown as

245 Horizon H1 in Figure 8B. Regionally, it is characterized by a parallel, laterally continuous seismic facies

246 with weak amplitude reflections (Figure 2D, 4A). However, directly beneath the seabed pockmarks, this

247 reflection character changes markedly, to a more discontinuous, or even chaotic seismic facies, with

248 strong local amplification of small reflection sediments (Figure 8B). Vertically stacked concave-upwards

249 reflections are commonly observed directly beneath the seabed pockmarks (Figure 8B).

250 These seismic characteristics collectively resemble zones of sediment disruption and remobilization

251 formed due to focused fluid expulsion and gas migration (Judd and Hovland, 2009; Moss and Cartwright,

252 2010; Plaza-Faverola et al., 2011; Andresen and Huuse, 2011). Given that the only region with this

253 disrupted seismic character occurs directly beneath the pockmarks, we interpret this seismic character to

254 be the product of widespread fluid expulsion spanning the full region of the disrupted zone. There are

255 seismic artifacts (transmission, attenuation) complicating the imaging of this disrupted volume, but these

256 are interpreted to contribute to the seismic disruption rather than be its exclusive cause.

\section{Middle Miocene Unconformity (Horizon H1)}

259 A number of strong amplitude anomalies are mapped at and just below the unconformity precisely in the

260 region below the pockmarks. Elsewhere, the unconformity is marked by a low to moderate amplitude

261 reflection. These amplitude anomalies are acoustically hard (positive acoustic impedance contrast), and

262 exhibit irregular planforms. These variably coalesce laterally where elongate portions follow the

263 intersection of the unconformity with the upper tip portions of polygonal faults developed within Unit 3

264 (Figure 4A-B, 8C). These amplitude anomalies are similar in size and acoustic character to hydrocarbon- 
related diagenetic zones that have been interpreted above many leaky hydrocarbon fields in the NW Shelf petroleum province (Cowley and O’Brien, 2000). They are also very similar in geometry and acoustic

267 character to methanogenic carbonate cemented layers within vertical gas migration zones (Ho et al. 2012).

268 Although attenuation is observed beneath these anomalies, as would be expected, there are no obvious

269 velocity pull-ups or push-downs directly beneath. This could be taken to indicate that any cemented zones 270 or diagenetically altered layers were too thin for a noticeable velocity effect.

271

\section{Unit 3}

273 This seismic stratigraphic unit (Trella/Giralia Limestone, Miria/Korojon/Toolonga Formation, and Gearle

274 Siltstone, Figure 2B) is characterized regionally throughout the survey area by low to high amplitude

275 reflections with laterally continuous acoustic expression (Figure 4A). Their continuity is, however,

276 disrupted by closely spaced polygonal faults that transect this interval (Figure 3B, 4A, 8D-E). A number

277 of amplitude anomalies are observed within Unit 3 (Figure 8D-E-F). These are distributed near the top of

278 Unit 3, where they consist of vertically stacked reflections marked by soft and hard reflection pairs

279 (Figure 8D), and near the base of the same unit, where they occur more as isolated soft anomalies (Figure

280 8E). Both stacked and isolated anomalies have rounded planform shape as observed on map view (Figure

281 8F). The anomalies in Unit 3 do not produce signal deterioration i.e. their hosting stratigraphy is well

282 imaged within and around the amplification (Figure 8D-E). Because of the dominant soft polarity and the

283 fact that these anomalies are only observed in a small region above the underlying gas-water contact of

284 the Scarborough Gas Field, we interpret these features as gas-related amplitude anomalies. The stacked

285 anomalies near the top of Unit 3 are therefore interpreted as vertical anomaly clusters (VACs, Foschi et

286 al., 2014).

\section{Unit 2}

289 This unit is the immediate top seal to the reservoir for the Scarborough Field (Muderong Formation,

290 Figure 2B), and comprises generally low amplitude reflections whose lateral continuity is disrupted by a 
291

292

lower tier of polygonal faults (Figure 3A, 4A). This is separated from the upper tier by a thin interval calibrated as the Windalia Radiolarite (H2, Figure 2B-C-D; Alexander et al., 1981). The only larger throw faults that transect this thin interval are the WNW-ESE and NNE-SSW trending tectonic normal faults that offset the top reservoir (Figure 3A, 5B). Small 100-meter's scale (328ft) amplitude anomalies are observed in the upper section of this interval (Figure 8G-H). These are characterized by a dominantly soft polarity with amplitude above the background level (Figure 8G). On map view they are characterized by closely spaced 10-meter's scale anomalies separated at the intersection with the polygonal faults (Figure $8 \mathrm{H})$. Because of the similarity with the other anomalies observed in Unit 3 we interpret these observed in Unit 2 as minor gas accumulations probably trapped within relatively higher porous intervals embedded within the Muderong Formation (e.g. Figure 6B, Scarborough-1, SWS \#53, \#52, \#132).

\section{Interpretation}

Collectively, the fluid escape features at the seabed, and the seismic amplifications are all consistent with dominantly vertical gas migration, albeit with minor components of lateral migration as part of the generally upwards tortuous pathways (Figure 9A-B). Since the area affected by these phenomena forms a well-defined region exclusively above and within the gas-water contact of the Scarborough Field, we agree with previous interpretations that this suite of seismic features represents a large leakage zone above the field (O’Brien and Woods, 1995; Cowley and O’Brien, 2000; Jablonski et al., 2013).

The vertically stacked amplitude anomalies argue strongly for dominantly sub-vertical to vertical, probably tortuous, gas migration pathways whose loci are at the center of these anomaly stacks (c.f. Foschi et al., 2018). This points to the presence of a large number of localized vertical fluid migration pathways within the shallowest overburden units (Units 3 and 4) (Figure 9). This is also strongly suggested by the distribution of pockmarks into five sub-areas (Figure 8A, 9A). The spacing of these pockmarks and the structure of the seal units in the regions between the areas argues against an alternative interpretation that all of the widely dispersed near surface leakage phenomena could be linked to any 
single leakage valve position. This is further emphasized by the presence of multiple, small scale gas

317 pockets within the seal (Unit 2, Figure $8 \mathrm{H}$ ), whose formation requires necessarily multiple loci and sub-

318 vertical migration pathways.

319 The most surprising feature of this leakage zone is the lack of large gas-related seismic anomalies within

320 Unit 2. This contrasts with many other leaky gas fields that typically have well defined gas chimneys

321 embedded within the overburden (e.g. Tommeliten Alpha; Arntsen et al., 2007). Instead, above

322 Scarborough, the evidence for leakage is almost entirely within the shallower units (3 and 4) rather than

323 the immediate top seal (Unit 2). There are two possible contributory factors for this. Firstly, the polygonal

324 faults may have acted as a highly efficient seal bypass system (Cartwright et al. 2007; Gay et al. 2007;

325 Seebeck et al., 2015) (Figure 9B), preventing any significant local storage of gas en-route. Secondly, the

326 dominantly claystone lithofacies of the Muderong Formation (Figures 2B, 6B) simply did not facilitate

327 the significant storage of gas during its passage upwards.

\section{DISCUSSION}

330 The complex leakage phenomena observed above the Scarborough Gas Field encompasses a region of the 331 top seal and overburden that extends vertically for over $700 \mathrm{~m}(2296 \mathrm{ft})$ and laterally for over $100 \mathrm{~km}^{2}$

$332\left(38.6 \mathrm{mi}^{2}\right.$; Figure 5B, 8A, 9A). Within this region of leakage, it is argued that there are a number of 333 dominantly vertical migration foci, resulting in the formation of pockmarks at the seabed. When viewed 334 in its entirety therefore, the leakage zone is a combined top seal and overburden volume that hosts a 335 complex plumbing system connecting the top reservoir to the seabed (Figure 9B).

336 The sub-vertical components of the plumbing allowing cross-stratal gas migration and seal bypass are 337 most likely the pre-existing polygonal faults (Figure 3), together with the smaller number of WNW and 338 NNE trending tectonic normal faults (Figure 5A-B). In addition, some vertical flow paths may have been 339 located coincident with the vertically stacked concave amplitude anomalies (Figure 8B, c.f. Foschi et al., 340 2018). 
Importantly, this wide distribution of and large spacing between the vertical foci within the leakage zone

342 argues that leakage could not be formed by a single valve point from the top reservoir, but instead argues

343 positively for the presence of a series of more widely distributed points of leakage over a broad region of

344 the crest of the trap (Figure 9B), which we term here Distributed Crestal Leakage. The distributed crestal

345 leakage covers a broad region of the underlying Scarborough Gas Field, but does not extend beyond the

346 lateral margin of the current GWC. Importantly, the distributed crestal leakage extends over a large

347 portion of the broader crestal part of the field, where there is up to $40 \mathrm{~m}(131 \mathrm{ft})$ of relief at the top

348 reservoir map (Figure 9A). This implies that the shallowest and deepest leakage loci would have been

349 positioned above gas columns differing in height by $40 \mathrm{~m}(131 \mathrm{ft})$ at the time of leakage.

\section{Timing of the leakage}

352 When did this distributed leakage occur? The timing of the leakage can be constrained from the 353 observation that there are present day seabed pockmarks. Hence the timing of the leakage 'event' is 354 sufficiently recent to have left a clear morphological expression of seafloor pockmarks over a broad area, 355 with no infilling or removal by erosion (Figure 8A). The absence of stacked pockmarks in the near 356 surface sediments (c.f. Andresen and Huuse, 2011) argues in favor of a single, well defined leakage 357 'event' rather than an episodic series of leakage events. The duration of the event was sufficiently short so 358 that no sign of cannibalization of adjacent pockmarks is seen in the seabed mapping (Figure 8B).

359 The timing of pockmark formation must post-date the youngest sediments that were eroded during 360 pockmark formation. The pockmarks form at the seabed, but given the limits of vertical seismic 361 resolution, it is not possible to differentiate pockmarks that formed recently with no subsequent sediment 362 fill, from those that formed some time ago that have subsequently experienced a drape depositional infill 363 (c.f. Moss et al. 2012). Modern deposition in this part of the passive margin is pelagic and sedimentation 364 rates are low (c. $20 \mathrm{~m} / \mathrm{Ma}$ [65 ft/Ma]), but the pristine geometry of the pockmarks imaged by the 3D 365 seismic argues that the maximum thickness of any possible drape of younger pelagic sediment would be 366 c. $5 \mathrm{~m}$ (16 ft; vertical resolution of the near seabed sediments). Nearby scientific boreholes (ODP sites 
762 and 763) show that near surface sediments can be assigned to the Middle to Late Quaternary in age

368 (Zone NN21b; Bolli et al. 1985). Hence, the leakage above the Scarborough Gas Field is interpreted to 369 have occurred at some time (duration unknown) within the last $250 \mathrm{Ka}$.

371 Mechanisms of seal failure

372 The mechanism of seal failure is assessed in this section based on the geometry of the trap, the sealing 373 properties of the immediate topseal (Muderong Formation), the geometry and seismic expression of the 374 leakage zone, and the potential and the present day MHC observed at the Scarborough Gas Field.

375 The two widely accepted general mechanisms for topseal failure are membrane and hydraulic leakage 376 (Watts, 1987). Since the membrane seal capacity for the Muderong Formation is uncalibrated in the study 377 area, we must extrapolate from the nearest studies which are based on core and mercury injection 378 capillary pressure data (Dewhurst et al., 2002; Kovack et al., 2004) and which indicate that a reasonable 379 value for membrane seal capacity would be in the order of $170-260 \mathrm{~m}(561-853 \mathrm{ft}$; Figure 7$)$. This 380 disparity between seal capacity measurements and observed column heights has been attributed to leakage 381 via critically stressed faults (Dewhurst and Hennig, 2003).

382 In contrast to the uncertainties in evaluating membrane seal capacity, the local calibration of the hydraulic 383 seal capacity of the Muderong Formation for the Scarborough Field (Figure 7) suggests a much higher 384 potential for retention of columns of at least $368 \mathrm{~m}(1207 \mathrm{ft})$, much greater than the trap capacity of 110 $385 \mathrm{~m}(360 \mathrm{ft})$. Comparing the two types of seal capacity, and notwithstanding the uncertainties, it thus seems 386 much more likely that the leakage event occurred by a process of membrane seal failure because the

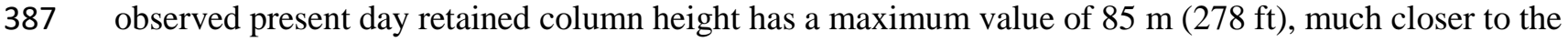
388 regional values of membrane seal capacity than the local hydraulic seal capacity. However, one additional 389 uncertainty that should be borne in mind are the in situ stress conditions during the period of leakage, and 390 whether these were likely to have led to critical stressing of any of the faults crossing the main seal units 391 (Dewhurst and Hennig, 2003). 
Based on the available seal property values, we suggest two alternative models, "Model A" and "Model B” (Figure 10), for the leakage event above the Scarborough Field and conclude the discussion with an assessment of their relative merits.

“Model A”: Membrane Seal Failure

397 We do not know if there is any leakage at present from the top of the reservoir, but there are no reported 398 indications of active leakage in the study area. We, therefore, assume that the $85 \mathrm{~m}(278 \mathrm{ft}) \mathrm{MHC}$ value is 399 an effective maximum seal capacity value for the Scarborough Gas Field at the present day. This effective 400 seal capacity would include the contributions of polygonal faults and fractures above the region with the 401 MHC. Because there are no obvious changes in the spacing, throw value or orientation of the polygonal 402 fault system across the structure (Figure 3), there is no obvious reason to invoke a lateral variation in 403 effective seal capacity, such that the regions down flank would most likely have a similar seal capacity. 404 Based on this, we suggest that a minimum leakage criterion for the downflank areas, with present day 405 column heights of c. $40 \mathrm{~m}(131 \mathrm{ft})$, would have been a value equivalent to the present day MCH, i.e. $85 \mathrm{~m}$ 406 (278 ft). This then implies that a minimum additional gas pressure of $0.35 \mathrm{MPa}$, equivalent to a column of $407 \sim 45 \mathrm{~m}(147 \mathrm{ft})$ of gas at identical reservoir P-T conditions would have been required to produce failure of 408 the topseal in the downflank regions. Such an additional pressure source could have arisen from a modest 409 increase in aquifer pressure, of $0.35 \mathrm{MPa}$ above the current hydrostatic condition, but we suggest that this 410 increase would need to have been relatively rapid in order to lead to synchronous leakage from both 411 crestal and downflank leakage loci (Figure 10). Alternatively, a surge in gas migration into the trap could 412 also have led to conditions favoring distributed leakage, but this would also have had to have been rapid.

413 Slow increase in the hydrocarbon column height across the field would have led instead to localized

414 crestal leakage (Figure 1) (Sales, 1997). 
417 In contrast to the conservative conditions discussed above for "Model A", the reservoir/aquifer conditions

418 for hydraulic seal failure are much more extreme. For purely hydraulic seal failure involving the

419 polygonal fault network and perhaps additionally the E-W trending tectonic faults, the gas pressure would

420 have needed to be greater than that equivalent to a >520 m (1706 ft) column height, to intersect the

421 fracture gradient window, and $368 \mathrm{~m}(1207 \mathrm{ft})$ to reopen and reactivate preexisting faults and fractures

422 (Figure 7). Since the spill point is only $110 \mathrm{~m}(360 \mathrm{ft})$ below the crest of the structure, such a large gas

423 column could not have accumulated, so the only way to achieve the necessary pressure is with some

424 combination of increased gas column and aquifer overpressuring. The aquifer overpressure required for a

425 gas column of a completely filled-to-spill structure would have been of the order of $3.5 \mathrm{MPa}$, which again

426 reduces to 2.1 MPa for preexisting faults and fractures (Figure 7). The build-up of this substantial

427 overpressure would also have to have been rapid, as with "Model A", or crestal leakage would dominate

428 and lead to pressure reduction before the full dimensions of the leakage zone could be established.

429 For failure of the topseal in shear mode, it is conceivable that much lower values of gas pressure could

430 have induced shear failure of the pre-existing faults and fractures in the topseal, and in turn led to leakage

431 from a number of fault-related loci. It is difficult to assess this possibility for the Scarborough Gas Field

432 (see Underschultz and Strand, 2016 for theoretical considerations of pressure induced reactivation of

433 critically stressed faults) because there are no cores calibrating the shear strength of the fractured

434 Muderong Formation and in situ stress conditions are also uncalibrated. The fact that a polygonal fault

435 system is pervasively developed within the seal and is clearly imaged by the seismic perhaps indicates the

436 presence of a network of sub-seismic fractures too (Cartwright, 2011), and it is certainly a possibility that

437 some subset of these fractures might have favorable orientations to be critically stressed in the present-

438 day stress field. If so, then increases in gas pressure at the reservoir/seal interface could then have

439 promoted leakage, as suggested by Dewhurst and Hennig (2003).

440

441 "Model A" versus "Model B" 
442 Two key questions need to be addressed in assessing the relative merits of the two models proposed here.

443 Firstly, would the specific leakage mechanism and pressure conditions lead to the observed leakage zone

444 characteristics, and secondly, how does each model accord with the observed timing of surface leakage

445 that formed the pockmark field?

446 For "Model A", the strength of the envisaged conservative pressure conditions is that it is much easier to

447 envisage how a modest increase in aquifer pressure could be achieved, and following leakage, why the 448 aquifer would then return to a background hydrostatic pressure, as currently observed. However, with 449 such a low overpressure, it is difficult to conceive that flux of gas from the reservoir through the very low 450 permeability Muderong Formation $(300 \mathrm{nD})$ would be high enough after c. $900 \mathrm{~m}$ ( $2952 \mathrm{ft})$ of vertical 451 ascent to lead to pockmark formation, sediment remobilization and seabed subsidence (Figure 8A, B and 452 D). It is also hard to understand why, in a membrane leakage model, there is not more evidence of gas 453 pockets trapped in the thin-bedded siltstones within the seal (Figure 6B) and overburden (e.g. Gearle 454 Siltstone, Unit 3, Figure 2B), since these would have been important percolation flow pathways for gas 455 migration through the generally fine-grained succession due to their orders of magnitude lower entry 456 pressure values (e.g. Nelson, 2009).

457 One major uncertainty in the membrane leakage analysis is the specific role of the polygonal faults. At

458 first inspection, these seem to offer the most obvious weak points for the seal, and since they are 459 pervasive throughout the Muderong Formation and much of the overburden, they offer plausible 460 pathways for leaking hydrocarbons. As argued above, they may lower the effective membrane seal 461 capacity compared to values at the core scale, but they cannot by themselves explain the $40 \mathrm{~m}(131 \mathrm{ft})$ 462 range in the top reservoir depth values and gas column values for the various leakage loci. To do so, we 463 would have to explain why the polygonal faults at the crestal location differ from those down flank in 464 their contribution to a two-fold apparent variation in effective seal capacity, when there is no seismically 465 visible evidence for any lateral variation in their structural characteristics (Figures 3 and 4).

466 For "Model B", a hydraulic mechanism is appealing, it is much more likely to deliver large fluxes of gas 467 through the fault and fracture networks by dilation under elevated pressure, since dilatant fractures would 
allow open aperture channel flow conditions across almost the full thickness of the overburden, or at least to within $100 \mathrm{~m}$ (328 ft) or so of the seabed (Unit 4; Figures 4A and 8A). However, even with some

470 element of critical stressing of a subset of the fracture population, the LOT data (Figure 7) imply a very

471 significant and rapid increase in aquifer pressure as a fundamental requirement to drive this leakage

472 mode. Although overpressured compartments of $20 \mathrm{MPa}$ above hydrostatic have been documented in

473 some region of the Northern Carnarvon Basin (e.g. He et al., 2002, $200 \mathrm{~km}$ to the SE of the study area)

474 there is no evidence in our study area to account for such a dramatic pressure increase. We cannot exclude

475 this Model as such, but the lack of a viable mechanism to explain even the conservative 2.1 MPa aquifer

476 pressure increase is a significant deficiency of this model at present.

477 On balance therefore, although neither model is without its weaknesses, we favor "Model A", and a 478 conservative view of the leakage mechanism as being dominated by membrane leakage processes.

\section{Implications}

481 The flux during the leakage event is unknown, but from the scale and mechanism of leakage proposed, we suggest that it must have been sufficient to exploit the enhanced permeability derived from pre-existing faults and form the large pockmark field observed at the seabed. However dramatic the scale of the

484 leakage zone is, it is nevertheless hazardous to view the volume of the leakage zone as a proxy for total 485 leaked hydrocarbon volumes. In the example we present here, it is likely that most of the leaked gas 486 bypassed most of the seal and overburden and that only a small fraction of the total leaked methane 487 remains trapped in the subsurface, as evidenced by the presence of shallow amplitude anomalies. In other 488 examples of leaky gas fields, the evidence for leakage is often expressed seismically as a gas chimney, 489 where large rock volumes within the chimney feature may contain only low saturation gas, distributed in 490 relatively small pockets (e.g. Arntsen et al. 2007). Much further work is therefore required before leakage 491 events like the one described here from Scarborough can be fully quantified. 
The main conclusions are as follows:

1. The Scarborough Gas Field, a 7.3 trillion cubic feet hydrocarbon accumulation located in the NW Shelf of Australia, experienced a major seal failure in the past $250 \mathrm{Ka}$.

2. The seal failure produced a $100 \mathrm{~km}^{2}\left(38 \mathrm{mi}^{2}\right)$ wide leakage zone composed of over 500 pockmarks and sediment remobilization at the seabed and stacked shallow gas accumulations in the overburden.

3. The geometry of the leakage zone is consistent with multiple points of seal failure from where the gas escaped from the reservoir to the water column bypassing efficiently the seal and the overburden.

4. The most likely cause of seal failure is by a rapid increase in aquifer pressure by a minimum value of c. $0.35 \mathrm{MPa}$. This would account for the c.40 $\mathrm{m}(131 \mathrm{ft})$ variation in the column heights presently found beneath the widely distributed leakage foci.

\footnotetext{
Alexander, R., Kagi, R.I. and Woodhouse, G.W., 1981. Geochemical correlation of Windalia oil and extracts of Winning Group (Cretaceous) potential source rocks, Barrow Subbasin, Western Australia. AAPG Bulletin, 65(2), pp.235-250.
}

Alrefaee, H. A., S. Ghosh, and M. I. Abdel-Fattah, 2018, 3D seismic characterization of the polygonal fault systems and its impact on fluid flow migration: An example from the Northern Carnarvon Basin, Australia: Journal of Petroleum Science and Engineering, v. 167, pp. 120-130.

Andresen, K.J. and Huuse, M., 2011. 'Bulls-eye' pockmarks and polygonal faulting in the Lower Congo Basin: relative timing and implications for fluid expulsion during shallow burial. Marine Geology, 279(1-4), pp.111-127.

Arntsen, B., Wensaas, L., Løseth, H. and Hermanrud, C., 2007. Seismic modelling of gas chimneys. Geophysics, 72(5), pp.SM251-SM259.

Bilal, A., McClay, K. and Scarselli, N., 2018. Fault-scarp degradation in the central Exmouth Plateau, North West Shelf, Australia. Geological Society, London, Special Publications, 476, pp.SP47611. 
Bailey, A.H., King, R.C., Holford, S.P. and Hand, M., 2016. Incompatible stress regimes from geological and geomechanical datasets: can they be reconciled? An example from the Carnarvon Basin, Western Australia. Tectonophysics, 683, pp.405-416.

Berg, R.R., 1975. Capillary pressures in stratigraphic traps. AAPG bulletin, 59(6), pp.939-956.

Boyd, R., Williamson, P. and Haq, B.U., 1992. Seismic stratigraphy and passive-margin evolution of the southern Exmouth Plateau. Sequence Stratigraphy and Facies Associations, pp.579-603.

Bolli H. M., Saunders J. B. \& Perch-Nielsen K. (eds.) 1985. Plankton Stratigraphy. VIII, 1032 pp. Cambridge, London, New York, New Rochelle, Melbourne, Sydney: Cambridge University Press.

Bruant, R., Guswa, A., Celia, M. and Peters, C., 2002. Safe Storage of CO 2 in Deep Saline Aquifers. Environmental Science And Technology-Washington DC-, 36(11), pp.240A-245A.

Cartwright, J., 2011. Diagenetically induced shear failure of fine-grained sediments and the development of polygonal fault systems. Marine and Petroleum Geology, 28(9), pp.1593-1610.

Cartwright, J., Huuse, M. and Aplin, A., 2007. Seal bypass systems. AAPG bulletin, 91(8), pp.1141-1166.

Chadwick, A., Arts, R., Bernstone, C., May, F., Thibeau, S. and Zweigel, P., 2008. Best Practice for the Storage of CO2 in Saline Aquifers-Observations and Guidelines from the SACS and CO2STORE projects (Vol. 14). British Geological Survey.

Chen, Z., Zhou, F. and Rahman, S.S., 2014. Effect of cap rock thickness and permeability on geological storage of CO2: laboratory test and numerical simulation. Energy Exploration \& Exploitation, 32(6), pp.943-964.

Cowley, R. and O'brien, G.W., 2000. Identification and interpretation of leaking hydrocarbons using seismic data: A comparative montage of examples from the major fields in Australia's northwest shelf and Gippsland basin. The APPEA Journal, 40(1), pp.119-150.

Dewhurst, D.N., Jones, R.M. and Raven, M.D., 2002. Microstructural and petrophysical characterization of Muderong Shale: application to top seal risking. Petroleum Geoscience, 8(4), pp.371-383.

Dewhurst, D.N. and Hennig, A.L., 2003. Geomechanical properties related to top seal leakage in the Carnarvon Basin, Northwest Shelf, Australia. Petroleum Geoscience, 9(3), pp.255-263.

Downey, M.W., 1984. Evaluating seals for hydrocarbon accumulations. AAPG bulletin, 68(11), pp.17521763.

Drenth, M., 2007. Petroleum and Minerals Industries in the Northwest Marine Region. International Risk Consultants Pty Limited, Report Number: ENV-REP-07-0086 Rev 0.

Du Rouchet, J., 1981. Stress fields, a key to oil migration. AAPG bulletin, 65(1), pp.74-85.

England, W.A., Mackenzie, A.S., Mann, D.M. and Quigley, T.M., 1987. The movement and entrapment of petroleum fluids in the subsurface. Journal of the Geological Society, 144(2), pp.327-347.

Foschi, M., Cartwright, J.A. and Peel, F.J., 2014. Vertical anomaly clusters: Evidence for vertical gas migration across multilayered sealing sequences. AAPG Bulletin, 98(9), pp.1859-1884.

Foschi, M., Cartwright, J.A. and MacMinn, C.W., 2018. Sequential vertical gas charge into multilayered sequences controlled by central conduits. AAPG Bulletin, 102(5), pp.855-883. 
Gay, A., Lopez, M., Berndt, C. and Seranne, M., 2007. Geological controls on focused fluid flow associated with seafloor seeps in the Lower Congo Basin. Marine Geology, 244(1-4), pp.68-92.

He, S., Middleton, M., Kaiko, A., Jiang, C. and Li, M., 2002. Two case studies of thermal maturity and thermal modelling within the overpressured Jurassic rocks of the Barrow sub-basin, north west shelf of Australia. Marine and Petroleum Geology, 19(2), pp.143-159.

Heggland, R., 1997. Detection of gas migration from a deep source by the use of exploration 3D seismic data. Marine Geology, 137(1-2), pp.41-47.

Hermanrud, C., Halkjelsvik, M.E., Kristiansen, K., Bernal, A. and Strömbäck, A.C., 2014. Petroleum column-height controls in the western Hammerfest Basin, Barents Sea. Petroleum Geoscience, 20(3), pp.227-240.

Heum, O.R., 1996. A fluid dynamic classification of hydrocarbon entrapment. Petroleum Geoscience, 2(2), pp.145-158.

Hillis, R.R., Sandiford, M., Reynolds, S.D. and Quigley, M.C., 2008. Present-day stresses, seismicity and Neogene-to-Recent tectonics of Australia's 'passive'margins: intraplate deformation controlled by plate boundary forces. Geological Society, London, Special Publications, 306(1), pp.71-90.

Ho, S., Cartwright, J.A. and Imbert, P., 2012. Vertical evolution of fluid venting structures in relation to gas flux, in the Neogene-Quaternary of the Lower Congo Basin, Offshore Angola. Marine Geology, 332, pp.40-55.

Ingram, G.M. and Urai, J.L., 1999. Top-seal leakage through faults and fractures: the role of mudrock properties. Geological Society, London, Special Publications, 158(1), pp.125-135.

Jablonski, D., Preston, J., Westlake, S., Gumley, C.M., 2013. Unlocking the origin of hydrocarbons in the central part of the Rankin Trend, Northern Carnarvon Basin, Australia. In: Keep, M., Moss, S.J. (Eds.), The Sedimentary Basins of Western Australia IV: Proceedings of the Petroleum Exploration Society of Australia Symposium Exploration Society of Australia, pp. 1-31.

Judd, A. and Hovland, M., 2009. Seabed fluid flow: the impact on geology, biology and the marine environment. Cambridge University Press.

Kovack, G.E., Dewhurst, D.N., Raven, M.D. and Kaldi, J.G., 2004. The influence of composition, diagenesis and compaction on seal capacity in the Muderong Shale, Carnarvon Basin. The APPEA Journal, 44(1), pp.201-222.

Locke, 2005. WA-1-R Scarborough-3 \& -3/CH1 Well Completion Report - Interpretive Volume. BHP Billiton Petroleum PTY. LTD. A.B.N. 97006918832.

Longley, I.M., Bradshaw, M.T. and Hebberger, J., 2001. AAPG Memoir 74, Chapter 15: Australian petroleum provinces of the twenty-first century.

Moss, J.L. and Cartwright, J., 2010. 3D seismic expression of km-scale fluid escape pipes from offshore Namibia. Basin Research, 22(4), pp.481-501.

Moss, J.L., Cartwright, J. and Moore, R., 2012. Evidence for fluid migration following pockmark formation: Examples from the Nile Deep Sea Fan. Marine Geology, 303, pp.1-13.

Nelson, P.H., 2009. Pore-throat sizes in sandstones, tight sandstones, and shales. AAPG bulletin, 93(3), pp.329-340. 
Nugraha, H.D., Jackson, C.A., Johnson, H.D., Hodgson, D.M. and Reeve, M.T., 2019. Tectonic and oceanographic process interactions archived in Late Cretaceous to Present deep-marine stratigraphy on the Exmouth Plateau, offshore NW Australia. Basin Research, 31(3), pp.405-430.

O'Halloran, 2006. Scarborough HEX03A 3D Seismic Survey - Interpretation Report WA-1-R Exmouth Plateau, BHP Billiton Petroleum PTY. LTD. A.B.N. 97006918832.

Plaza-Faverola, A., Bünz, S. and Mienert, J., 2011. Repeated fluid expulsion through sub-seabed chimneys offshore Norway in response to glacial cycles. Earth and Planetary Science Letters, 305(3-4), pp.297-308.

Rudolph, K.W. and Goulding, F.J., 2017. Benchmarking exploration predictions and performance using $20+$ yr of drilling results: One company’s experience. AAPG Bulletin, 101(2), pp.161-176.

Sales, J.K., 1997. AAPG Memoir 67: Seals, Traps, and the Petroleum System. Chapter 5: Seal Strength vs. Trap Closure--A Fundamental Control on the Distribution of Oil and Gas.

Schowalter, T.T., 1979. Mechanics of secondary hydrocarbon migration and entrapment. AAPG bulletin, 63(5), pp.723-760.

Seebeck, H., Tenthorey, E., Consoli, C. and Nicol, A., 2015. Polygonal faulting and seal integrity in the Bonaparte Basin, Australia. Marine and Petroleum Geology, 60, pp.120-135.

Underschultz, J. and Strand, J., 2016. Capillary seal capacity of faults under hydrodynamic conditions. Geofluids, 16(3), pp.464-475.

Watts, N.L., 1987. Theoretical aspects of cap-rock and fault seals for single-and two-phase hydrocarbon columns. Marine and Petroleum Geology, 4(4), pp.274-307.

Widess, M.B., 1973. How thin is a thin bed?. Geophysics, 38(6), pp.1176-1180. 
Figure 1. A, cartoon and pressure-depth plot of a simplified gas accumulation hosted within a representative sand interval and trapped by a representative seal. At the base of the seal the gas exerts a pressure proportional to the maximum hydrocarbon column (MHC). The MHC is located at the shallowest point of the reservoir. The pressure exerted by the gas is insufficient to fracture the seal i.e. the gas gradient (GG) does not intersect the fracture gradient (FG); HG = hydrostatic gradient. $\mathrm{B}$, the increase of the MHC (during gas charging) produces a higher gas pressure, which is sufficient to breach the seal and produce leakage. The leakage will occur at the MHC and within the nearby region (localised crestal leakage).

Figure 2. A, The Exmouth Plateau is located in the North West shelf of Australia (inset). The threedimensional seismic data and two regional two-way time (TWT) profiles shown in this study are located along a NE-SW trending anticline within the Exmouth Plateau. ODP 763 provides information for the dating of the sediments near the seabed, which based on radiolarians collected at ODP Site 763 (c. tuberose and b. invaginata), are Middle to Late Quaternary in age (Bolli et al., 1985). B, representative stratigraphic column of the Exmouth Plateau (from Nicoll et al., 2009), with the main subdivision in units described in the text. Bold names refer to formations encountered by the exploration boreholes intersecting the 3D seismic volume. C, regional profile depicting the regional structural and stratigraphic features of the basin, with gross subdivision in 4 main units. $\mathrm{D}$, regional profile intersecting the gas water contact (GWC) of the Scarborough Gas Field.

Figure 3. A, coherence attribute and depth structural maps of the base of the Muderong Formation intersected by the Triassic normal faults and the polygonal faults (refer to Figure 4A for the position). The polygonal faults are closely spaced and exhibit polygonal pattern without any significant evidence of preferential strike development. B, time-slice of a coherence attribute volume across the center of Unit 3 depicting the polygonal character of the polygonal faults (refer to Figure 4A for the position). The polygons do not show any evidence of preferential strike development. C, time-slice of a coherence attribute volume across the center of Unit 4 (refer to Figure 4A for the position). Unit 4 does not show any evidence of polygonal faults. At the center of the map a large disruption zone can be observed.

Figure 4. A, depth seismic cross section (see Figure 4 for line location) depicting the main structural elements of the Scarborough Gas Field and the leakage zone. The Scarborough Gas Field exhibits a gas water contact $(\mathrm{GWC})$ at $1916 \mathrm{~m}(6286 \mathrm{ft})$. Horizon $3(\mathrm{H} 3)$ represents the top of the reservoir of the combined Upper and Lower Fans. Unit 2 represents the sealing unit and Unit 3 and 4 the overburden. Unit 2 and 3 are offset by two independent polygonal fault systems (PFS). Amplitude anomalies (AAs) are observed at the top of Unit 3 (described later). At the seabed surface pockmarks (PM) affect the seabed morphology (described later). B, displacement versus depth profiles of five representative polygonal faults across Unit 2 (see Figure 4A for location). The maximum displacement is observed at around 300 m (984 ft) below the Middle Miocene Unconformity (H1, datum). The upper tip of the polygonal faults is truncated at $\mathrm{H} 1$ suggesting that the top was eroded during the formation of the unconformity. $\mathrm{C}, 2 \mathrm{x}$ close up (see Figure 4A for location) showing the onlapping geometry of Unit 4 on H1.

Figure 5. A, depth structural map of $\mathrm{H} 3$ (top reservoir of the combined Lower and Upper Fans) around the 3D seismic volume. The map was constructed using regional two-way-time profiles. The map was depth converted using an average interval velocity for the seal, the overburden and the water. The spill point (SP) of H3 is located in the NE corner of the map at a depth of 1960-1965 m (6430-6446 ft). B, depth structural map of $\mathrm{H} 1$ with structural elements, gas water contact (GWC) and position of the exploration borehole. The GWC is located at an average depth of 1900-1920 m (6233-6299 ft). 
Figure 6. A, pressure-depth plot derived from data retrieved at the exploration boreholes Scarborough-1 to 5 (no data was available from well North Scarborough-1; pressure data at Scarborough-3 is offset because of a different gauge device). The data shows that the water gradient is in hydrostatic equilibrium at the well locations. The gas gradient is constant for all the wells suggesting good hydraulic communication within the reservoir. The gas water contact (GWC) can be observed at the intersection between the hydrostatic and the gas gradients at c. $1936 \mathrm{~m}$ (6351 ft) measured depth (MD; $1916 \mathrm{~m}$ [6286 $\mathrm{ft}]$ true vertical depth at sea surface, TVDSS). The top reservoir (top Upper Fan, Top UF). The fracture gradient was constructed using leak-off test (LOT) pressures collected at different depth intervals. A linear gradient was used. B, gamma ray versus depth cross plot from the exploration boreholes Scarborough-1 to 5 with lithological information derived from side-wall samples (SWS) and cuttings. The Muderong Formation is characterised by a variable thickness of 150 and $220 \mathrm{~m}$ (492 and $721 \mathrm{ft}$ ). It is characterised by large gamma ray readings and is dominated by claystone with a few intercalations of calcareous siltstone.

Figure 7. Pressure-depth plot derived from data retrieved at the exploration boreholes Scarborough-1 to 5 (no data was available from well North Scarborough-1; see Figure 6A for reference). The fracture gradient was constructed using leak-off test (LOT) pressures collected at different depth intervals. Using a linear interpolation a fracture pressure gradient of $16.3 \mathrm{MPa} / \mathrm{km}$ was obtained (this gradient is compared to what obtained by Dewhurst and Hennig, 2003, inset). Using the gas pressure gradient retrieved from the borehole Scarborough-1 to 5 a series of gas columns were plotted. The gas gradient exerted by the current gas column and up to the spill point is not sufficient to breach the seal. A hypothetical gas column

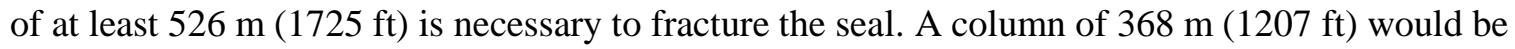
required to reopen or reactivate pre-existing faults and fractures. The plot also shows the hypothetical gas columns required to capillary invade the seal (>171 m [561 ft]). These are estimated based on two works completed by Dewhurst et al., 2002 (Pce $\left.{ }^{1}\right)$ and Kovack et al., 2004 (Pce ${ }^{2}$ (see text).

Figure 8. Composite figure of the main leakage phenomena observed above the Scarborough Gas Field. A, seabed map showing the position of the 522 pockmarks (yellow dots) enclosed within five pockmark regions (R1 to R5, dashed blue line). The pockmark regions are defined using a density function calculated from the distribution of the pockmarks, where grey is low density and yellow is high density. $\mathrm{B}$, seismic cross section depicting the shallow section of the study area (see Figure 8B for line location). Unit 4 exhibits concave upward reflections below the pockmarks interpreted as sediment remobilization and collapse produced by the migration of fluids. $\mathrm{C}$, amplitude map showing the amplitude response of horizon H1 (Middle Miocene Unconformity; see figure 8A for map location). The root-mean square (RMS) amplitude response shows stellate anomalies distributed along the intersection of polygonal faults (PF) and H1 surface. These suggest a migration mechanism dominated by vertical migration along polygonal faults (see text). D, seismic cross section depicting a representative vertical anomaly cluster (VAC, see Figure 8C for line location). These VACs are characterized by a limited extent and are composed of 4-5 anomalies each. The polygonal fault system (PFS) may prevent significant lateral migration. E, seismic cross section depicting amplitude anomalies encountered in the lower section of Unit 3 (see Figure 8C for line location). F, amplitude extraction showing the shape of the amplitude anomalies (AA) in the lower section of Unit 3 and the polygonal faults (PF). G, seismic cross section showing the acoustic response of minor amplitude anomalies observed in Unit 2. These are a few tens of meters in size and are located just a few hundreds of meters above the top reservoir $(\mathrm{H} 3)$. $\mathrm{H}$, amplitude map showing the acoustic characteristic of the amplitude anomalies (AA) observed in Unit 2. These are grouped in small ensembles separated by polygonal faults (PF). 
Figure 9. A, distribution of leakage phenomena observed above the Scarborough Gas Field (gas water contact, GWC, after Locke, 2005) and depth contour of the top reservoir (Horizon H3). There is a vertical stacking of the individual amplitude anomalies and pockmarks observed at the different units above the gas field. The leakage phenomena are located along the tectonic normal faults, above structural crests and along the flanks of the structural closure. Importantly, the leakage phenomena are located above gas columns of different heights. B, synoptic section showing the shallow plumbing system above the Scarborough Gas Field. The occurrence of deep and shallow anomalies and the pockmarks at the seabed, and the lack of signal deterioration, allows reconstructing the likely scenario for gas migration across the seal and the overburden (Unit 2 and 3). The polygonal faults seems playing a dominant role as seal bypass. The lack of prominent amplitude anomalies indicate the poor storage capacity of Unit 2 and 3. The occurrence of multiple amplitude anomalies near the top reservoir, and importantly within the seal (Unit 2), implies the presence of multiple valve points or loci from where the gas leaks across the seal and the overburden.

Figure 10. Simplified cartoons showing hypothetical scenarios of gas leakage above a gas field characterized by a maximum seal capacity equivalent to an $85 \mathrm{~m}(278 \mathrm{ft})$ gas column, and maximum trap capacity of $\sim 110 \mathrm{~m}(360 \mathrm{ft})$. The seal and the overburden are both affected by polygonal faults. Model A: a rapid increase of gas column (up to the spill point), or aquifer pressure, results into a sudden overpressure of about $0.35 \mathrm{MPa}$. This overpressure is sufficient to produce a capillary failure at the crest and in the downflank regions of the seal where the gas column is $40-45 \mathrm{~m}(131-147 \mathrm{ft})$. The capillary leakage is characterized by a relatively weak gas flow across more permeable routes, such as the polygonal faults. Model B: a rapid increase of aquifer overpressure of $3.26 \mathrm{MPa}$ dilates preexisting faults and fractures. The large hydrocarbon flow across the hydraulically opened faults produces a large leakage zone consisting of seabed pockmarks, sediment remobilization and seabed collapse. 


\section{FIGURE 1}

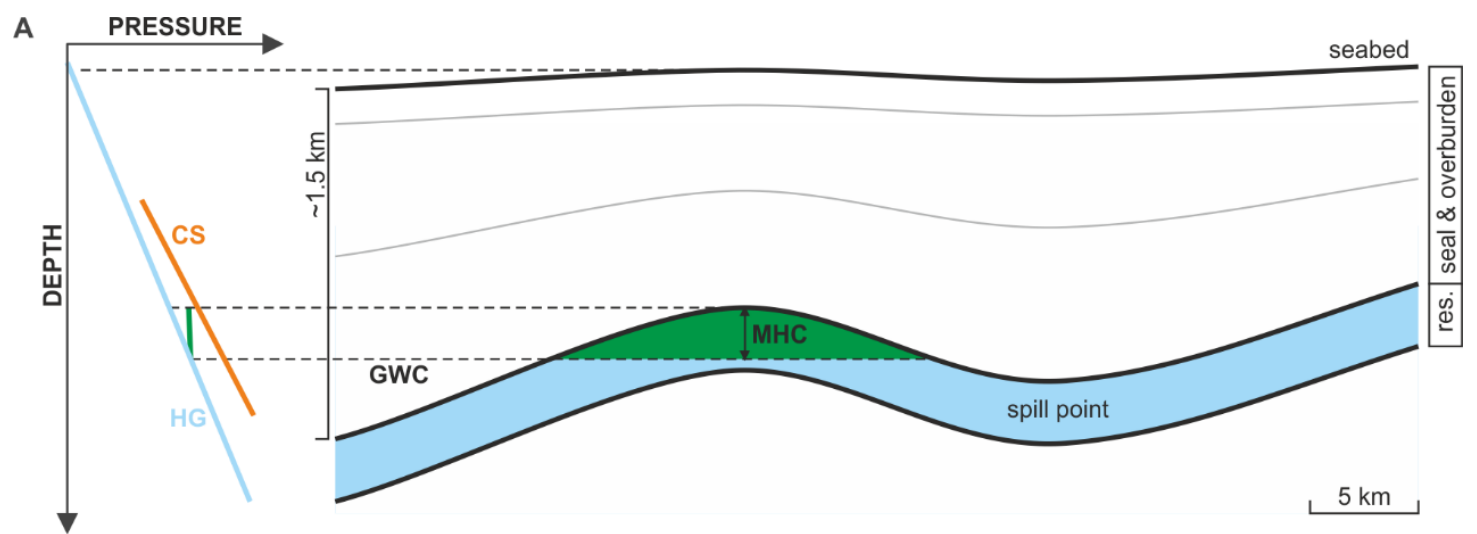

735

B

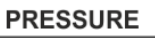

B PRESSURE

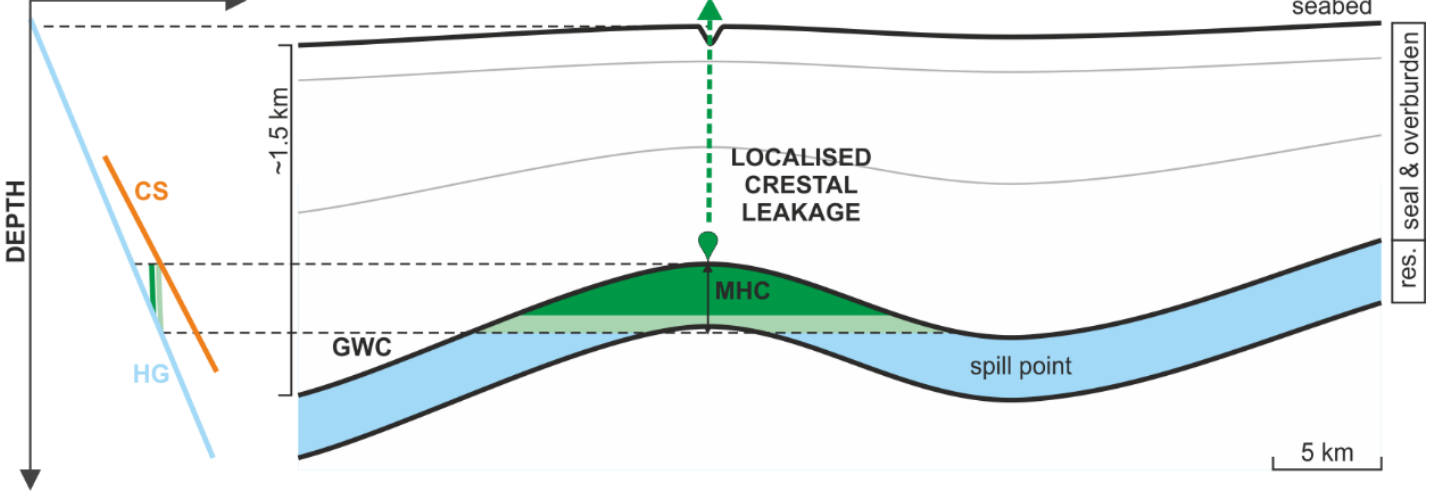

736 
FIGURE 2
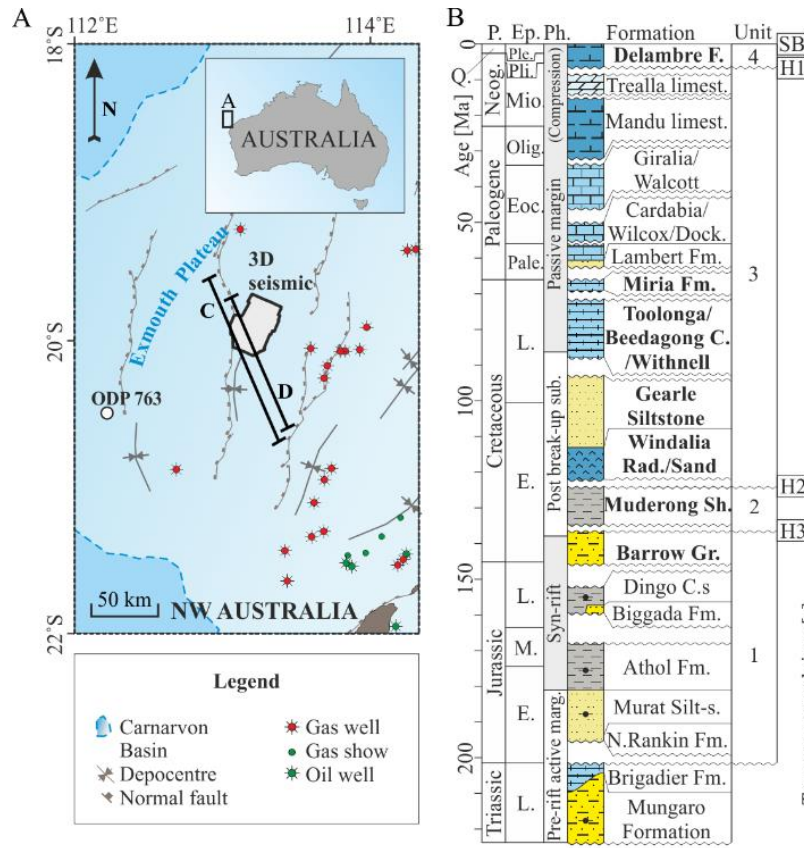

\begin{tabular}{|c|c|c|}
\hline \multicolumn{3}{|c|}{ Legend } \\
\hline $\begin{array}{l}\text { Siltstone } \\
\text { Mudstone } \\
\text { M. Limestone } \\
\text { Radiolarite }\end{array}$ & $\begin{array}{l}\text {. Sandy siltstone } \\
\text { Calcilutite } \\
\text { Sandstone } \\
\text { Dolomite }\end{array}$ & $\begin{array}{l}\text { 田 Chalk } \\
\text { - Source rock } \\
\text { H Horizons }\end{array}$ \\
\hline
\end{tabular}

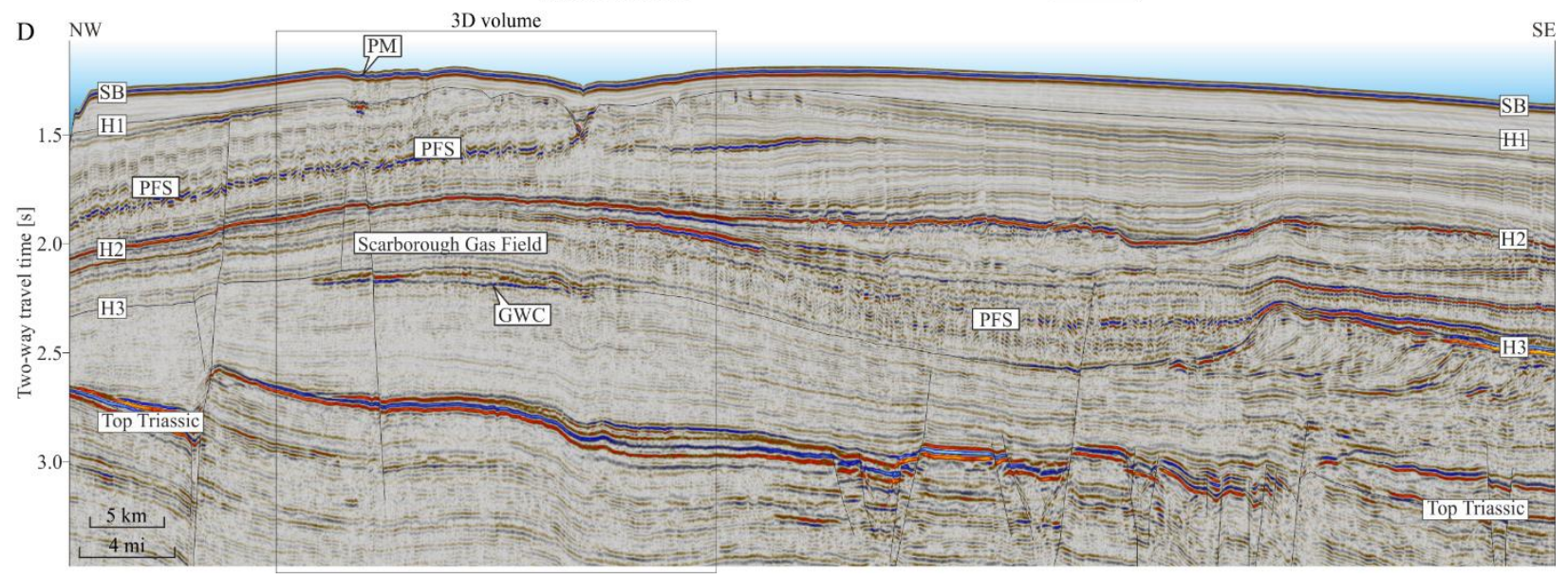

3D volume

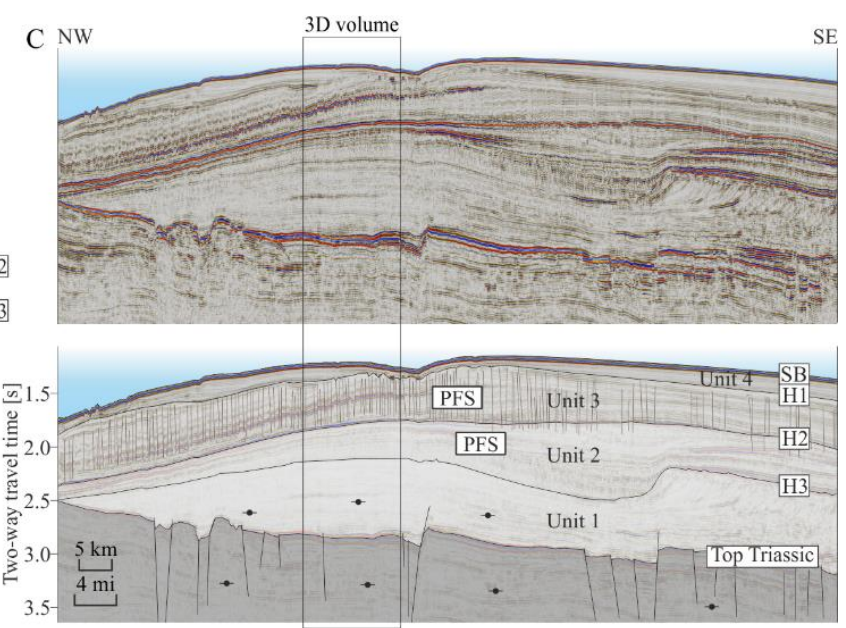


FIGURE 3
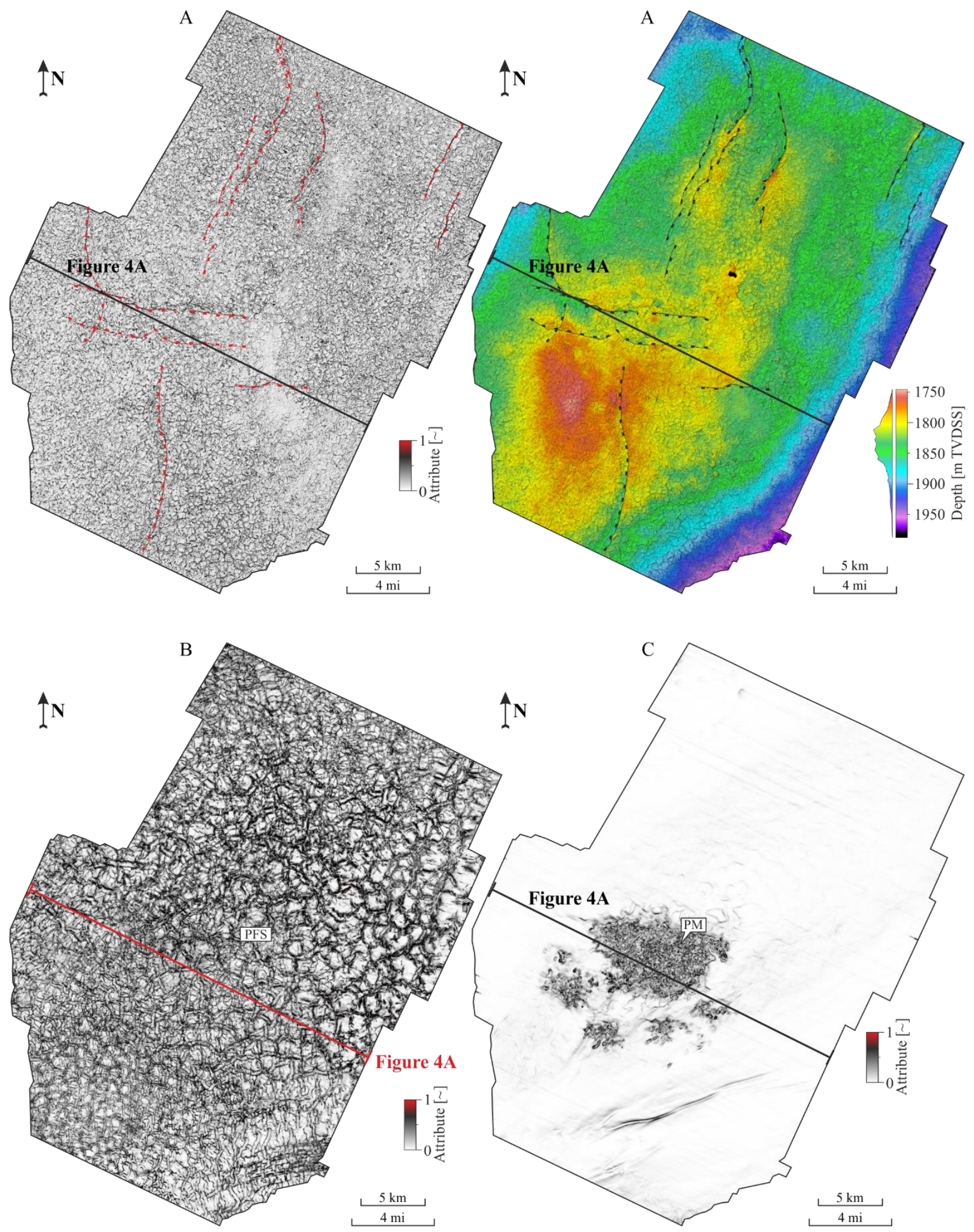


\section{FIGURE 4}
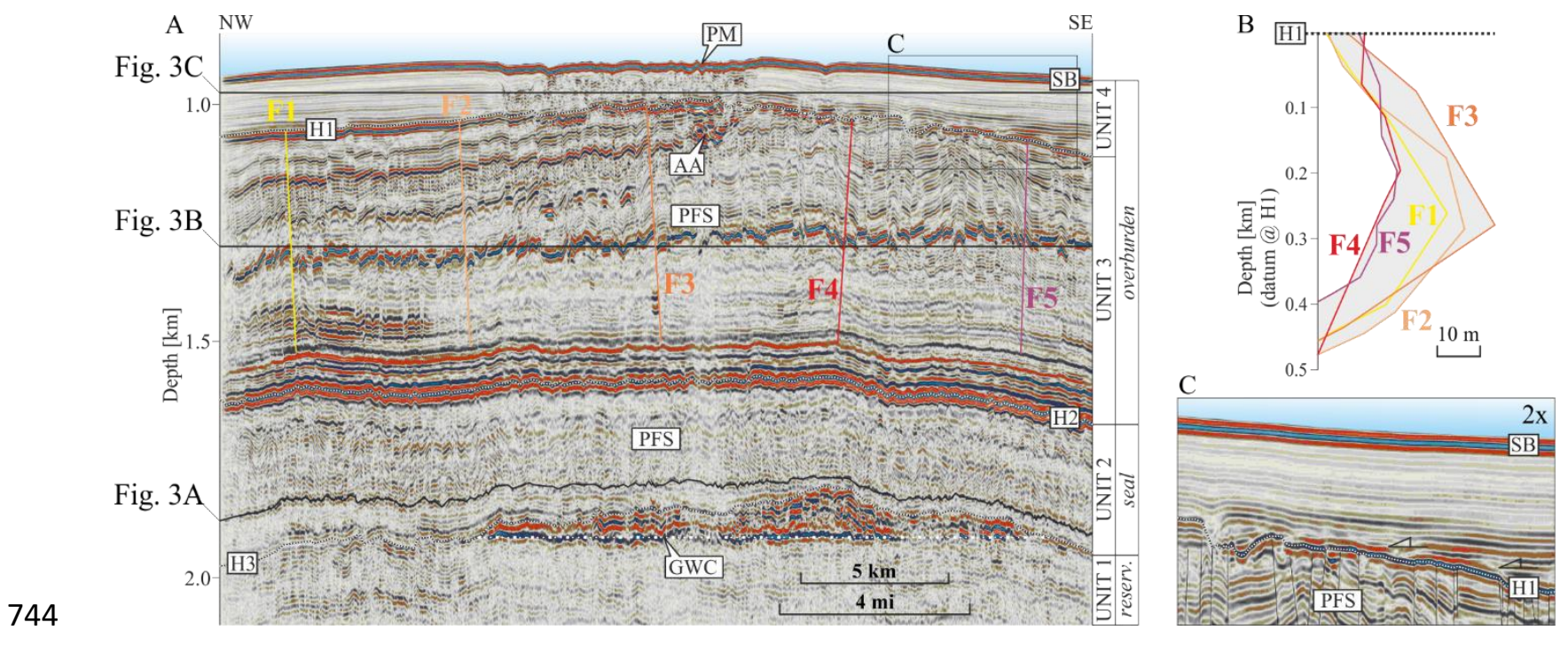

745 
FIGURE 5

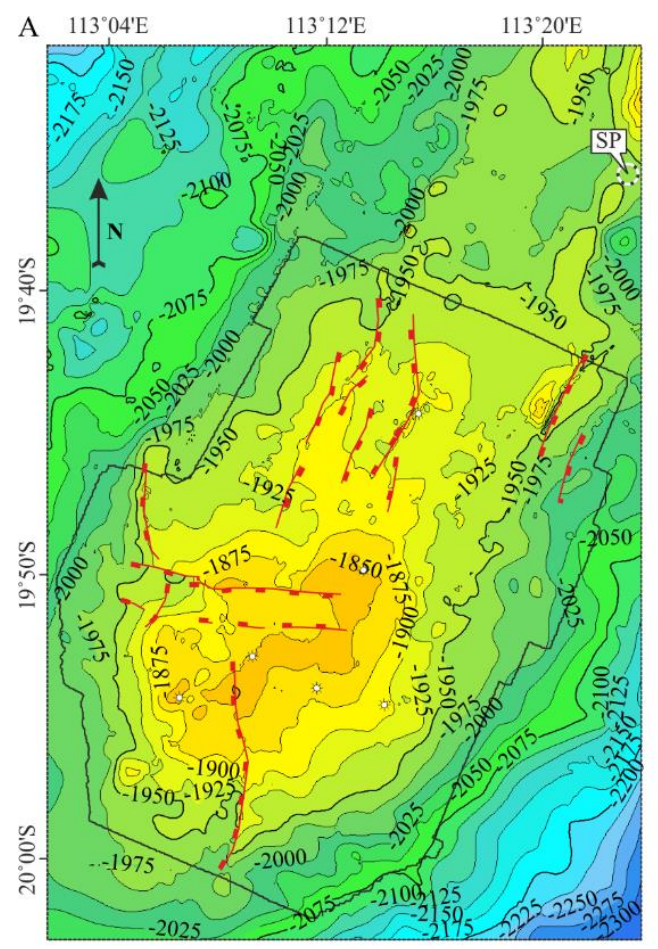

\begin{tabular}{|l|}
\multicolumn{1}{c|}{ Legend } \\
H3 depth contour [25 m spacing] \\
(2D seismic grid TWT) \\
D 3D seismic volume \\
Normal faults \\
Exploration well \\
\hline
\end{tabular}

$\begin{array}{r}5 \mathrm{~km} \\ 4 \mathrm{mi} \\ \hline\end{array}$
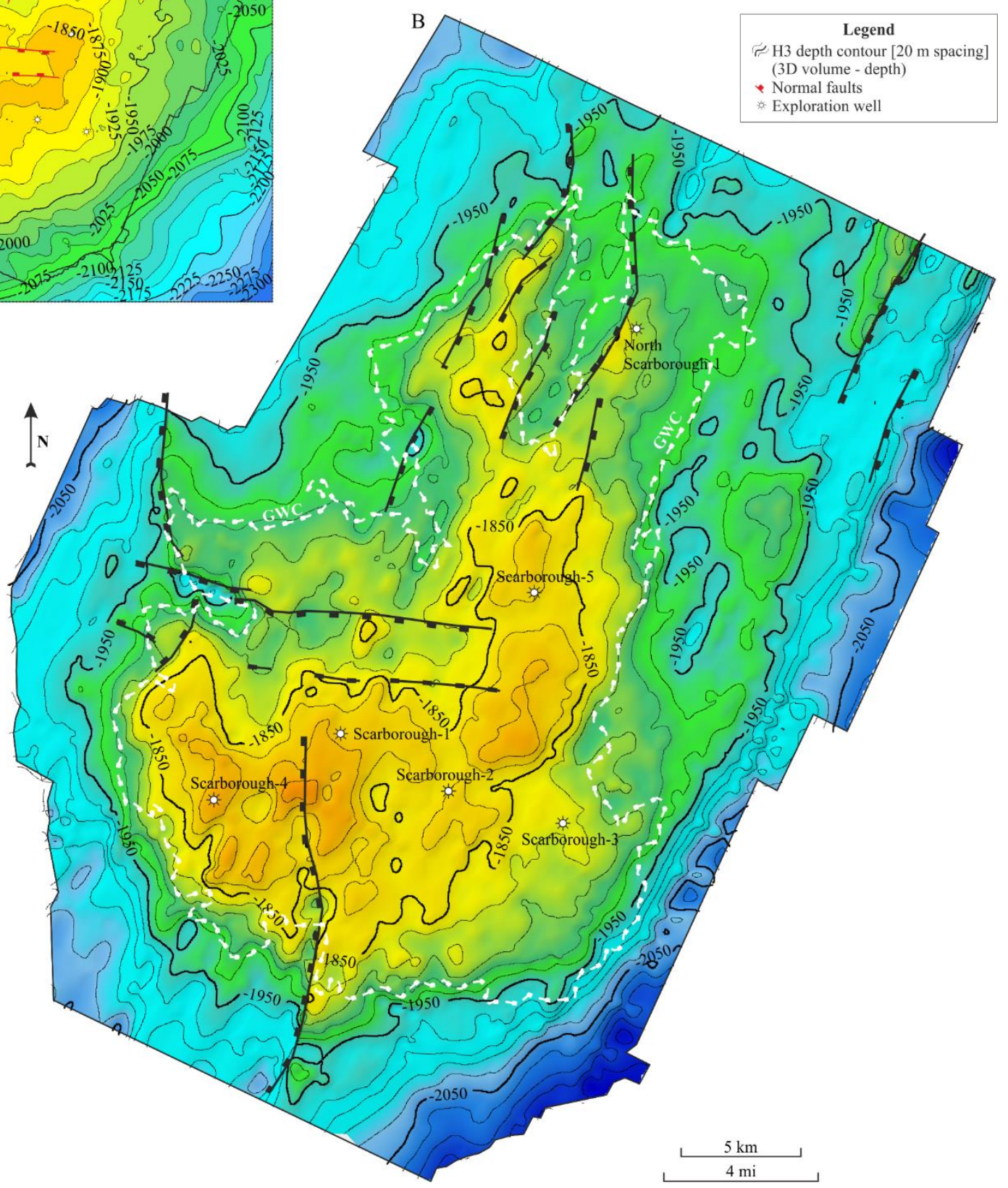
FIGURE 6

A

Pressure [MPa|
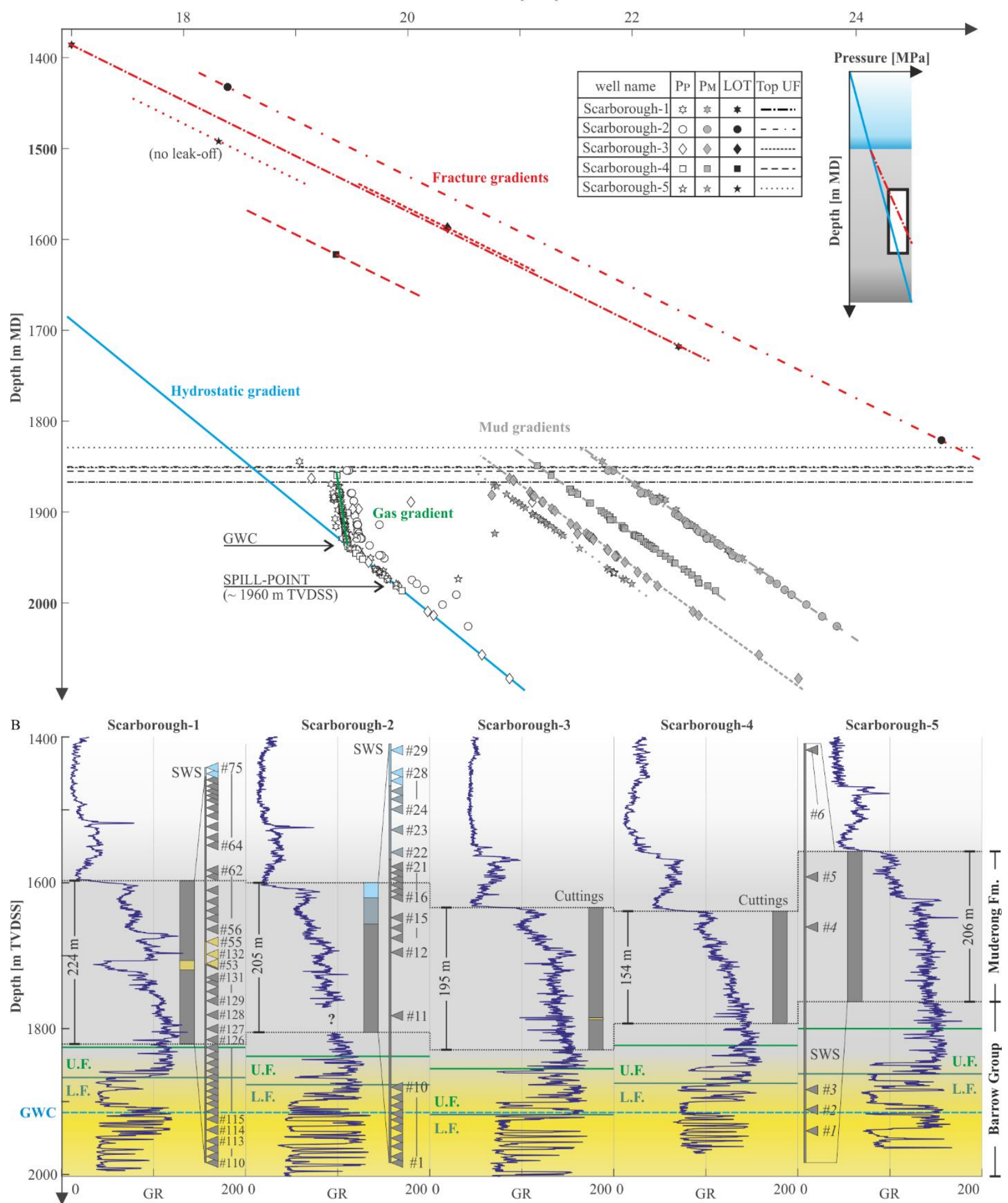


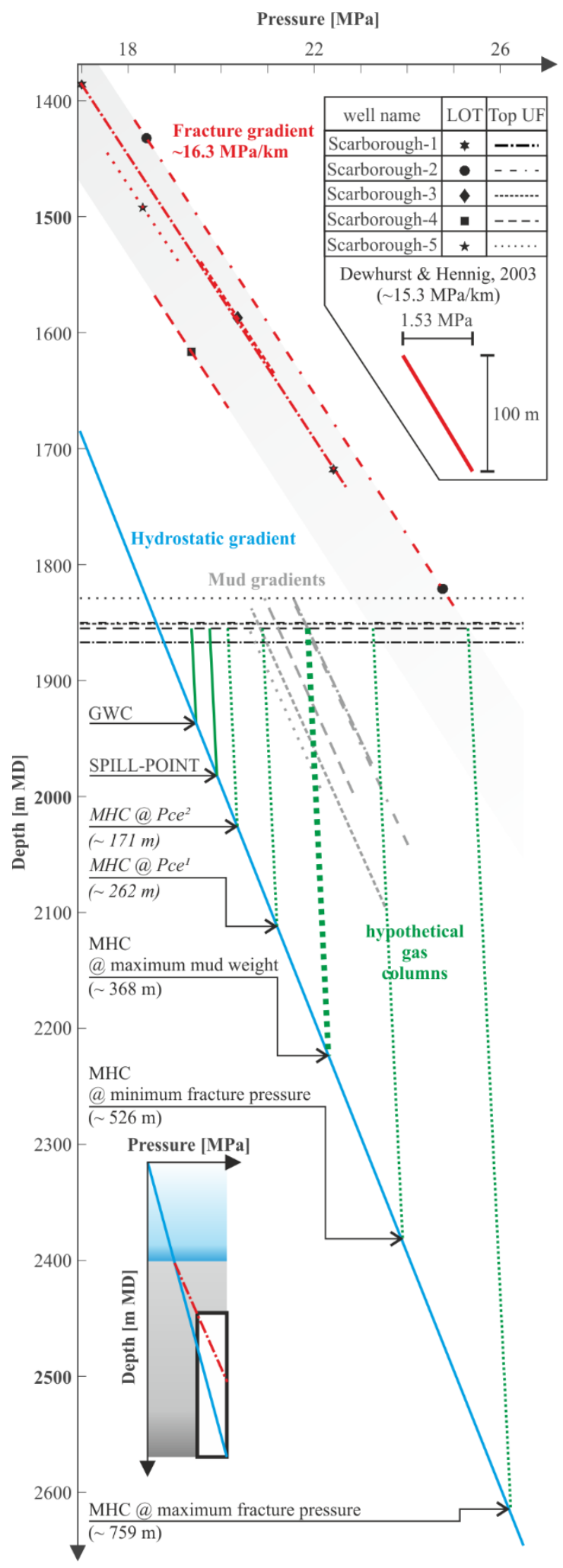



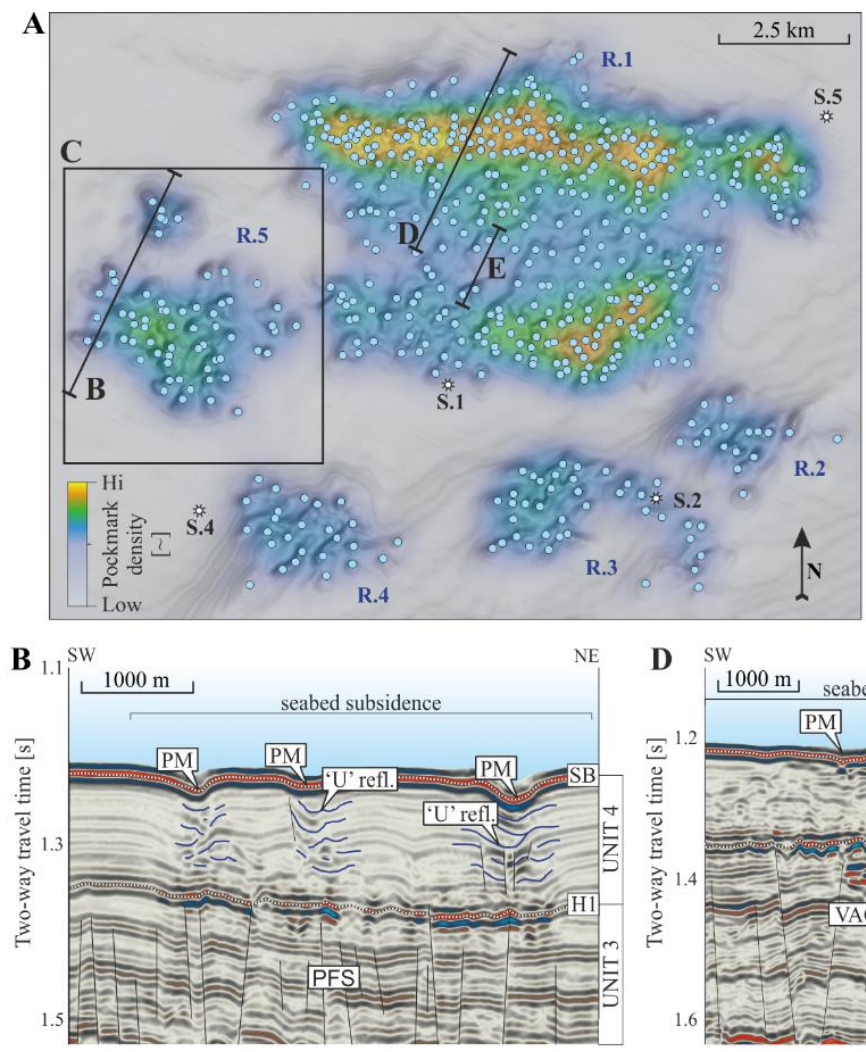

D $\mathrm{SW}$
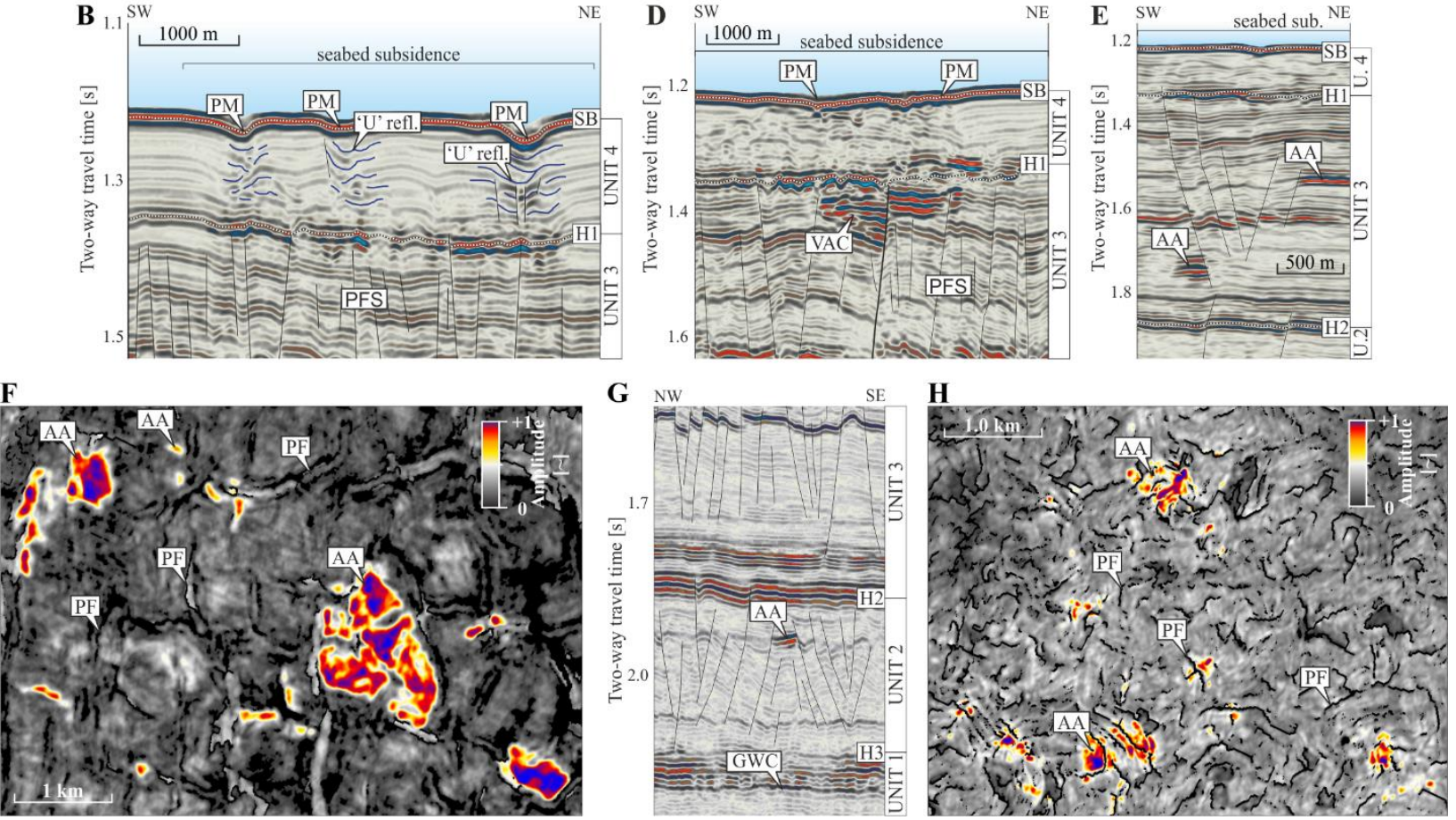

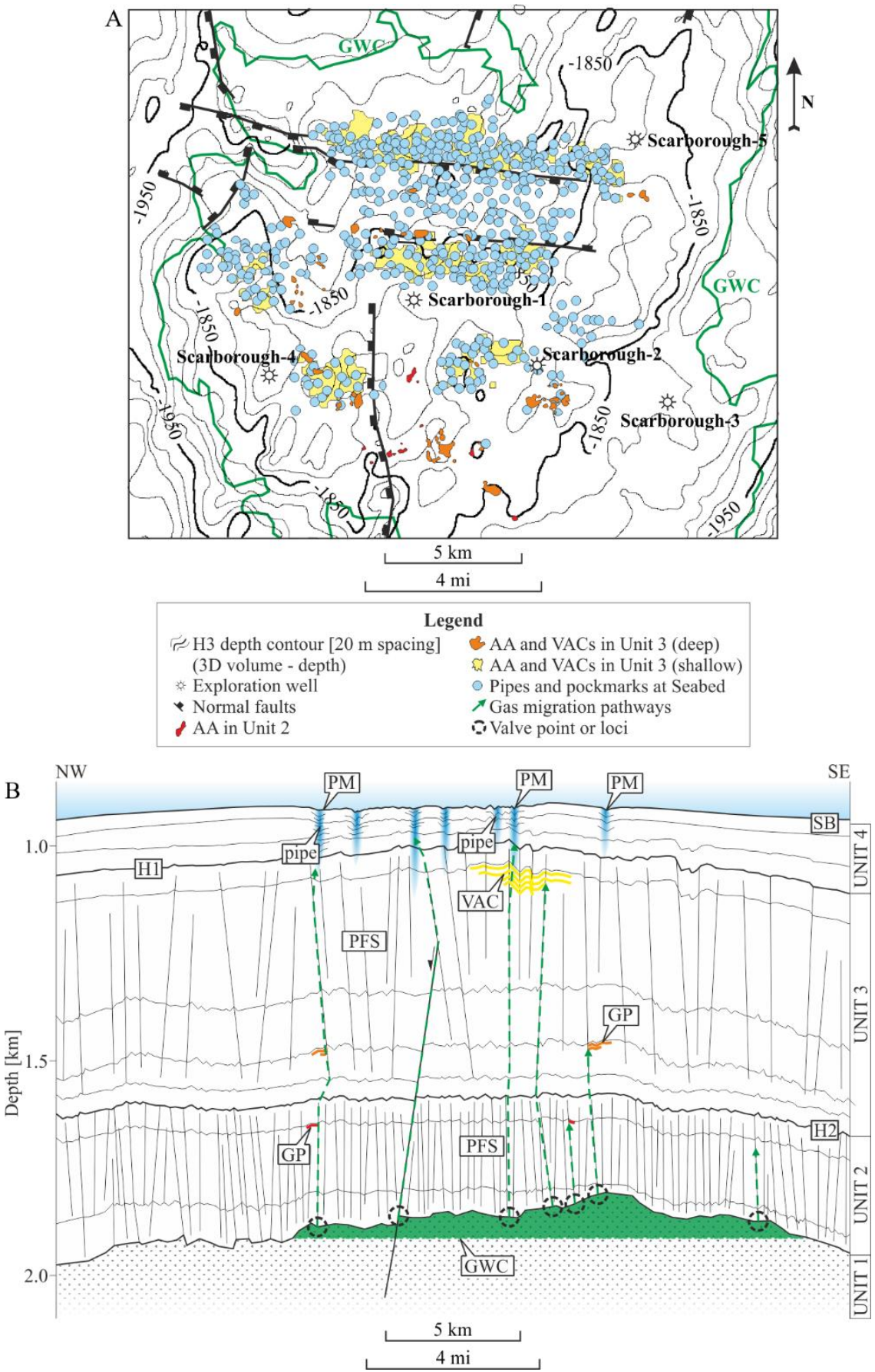

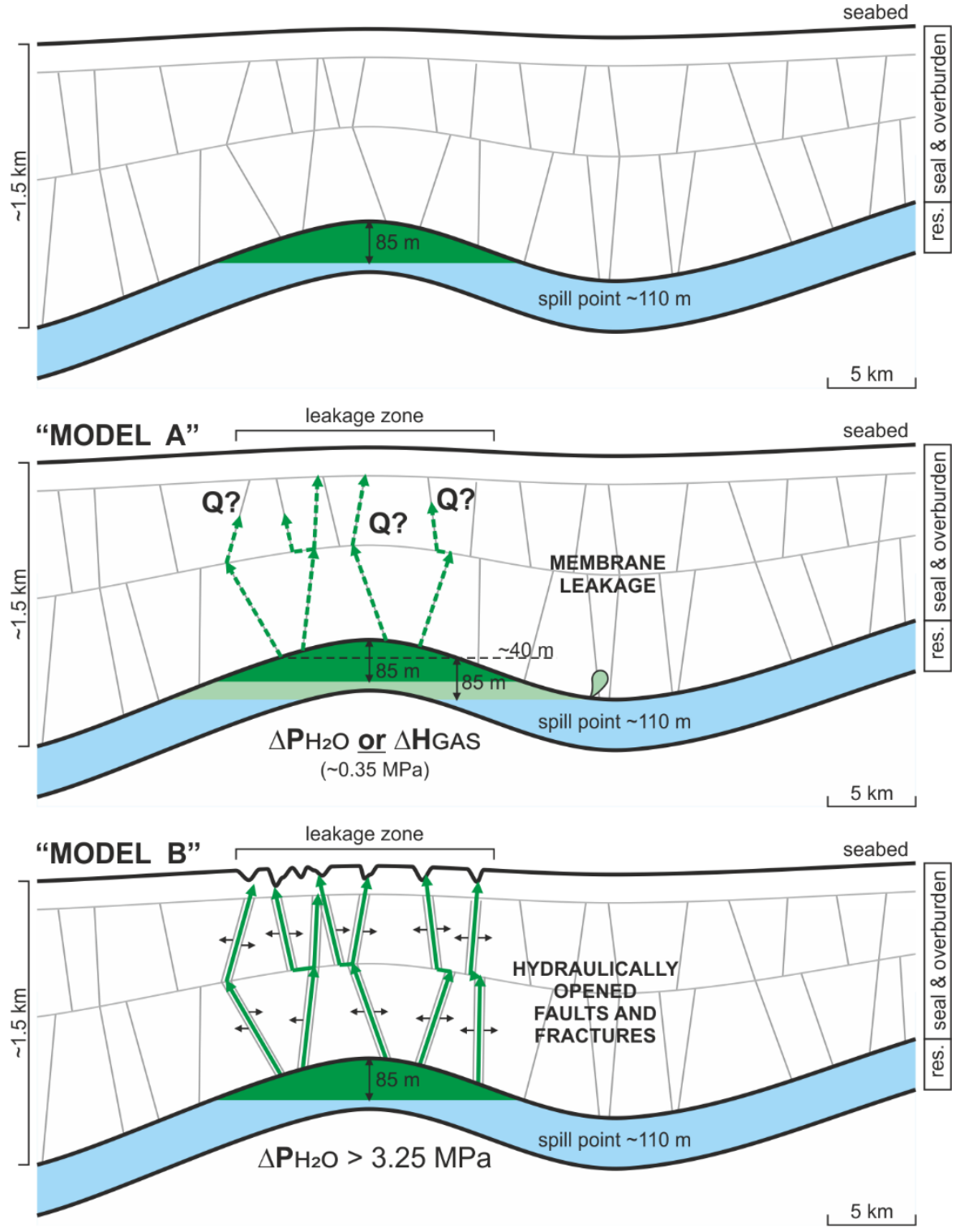